\title{
Article
}

\section{Electrochemical oxidation of a highly soluble redox mediator in aqueous solution for energy conversion}

Keisuke Obata, Liga Stegenburga, Yanlong Zhou, and Kazuhiro Takanabe

ACS Sustainable Chem. Eng., Just Accepted Manuscript • DOI: 10.1021/

acssuschemeng.9b00263 - Publication Date (Web): 07 Mar 2019

Downloaded from http://pubs.acs.org on March 14, 2019

\section{Just Accepted}

"Just Accepted" manuscripts have been peer-reviewed and accepted for publication. They are posted online prior to technical editing, formatting for publication and author proofing. The American Chemical Society provides "Just Accepted" as a service to the research community to expedite the dissemination of scientific material as soon as possible after acceptance. "Just Accepted" manuscripts appear in full in PDF format accompanied by an HTML abstract. "Just Accepted" manuscripts have been fully peer reviewed, but should not be considered the official version of record. They are citable by the Digital Object Identifier (DOI尺). "Just Accepted" is an optional service offered to authors. Therefore, the "Just Accepted" Web site may not include all articles that will be published in the journal. After a manuscript is technically edited and formatted, it will be removed from the "Just Accepted" Web site and published as an ASAP article. Note that technical editing may introduce minor changes to the manuscript text and/or graphics which could affect content, and all legal disclaimers and ethical guidelines that apply to the journal pertain. ACS cannot be held responsible for errors or consequences arising from the use of information contained in these "Just Accepted" manuscripts. 


\section{Electrochemical oxidation of a highly soluble redox}

\section{mediator in aqueous solution for energy conversion}

Keisuke Obataa, Liga Stegenburga ${ }^{a}$, Yanlong Zhoü, and Kazuhiro Takanabe ${ }^{a, b, *}$

aKing Abdullah University of Science and Technology (KAUST), KAUST Catalysis

Center (KCC) and Physical Sciences and Engineering Division, 4700 KAUST, Thuwal

23955-6900, Saudi Arabia

${ }^{b}$ Department of Chemical System Engineering, School of Engineering, University of

Tokyo, 7-3-1 Hongo, Bunkyo-ku, Tokyo 113-8656, Japan

*Corresponding author: Kazuhiro Takanabe, takanabe@chemsys.t.u-tokyo.ac.jp

\section{ABSTRACT}

An efficient and cost-effective electrochemical energy storage/conversion technique is needed to store electricity from intermittent renewable energy sources. Although 
electrochemical water splitting into hydrogen and oxygen is extensively studied, it suffers from kinetically-sluggish oxygen evolution reactions at extreme $\mathrm{pH}$ conditions. In this work, we investigated the oxidation of soluble redox species as an alternative anodic reaction, the kinetics of which have highly reversible characteristics on various electrode surfaces. The redox potential can be readily tuned by the ligand upon the formation of metal complexes, which provides various voltage options to develop electrochemical devices. The facile kinetics lead to diffusion overpotential being a major contribution of the electrochemical performance. Near neutral $\mathrm{pH}$ region was effectively chosen because it allows the versatile and safe operation with a reasonable voltage option. To overcome the diffusion issue, the solubility of redox species and the diffusion coefficient determined by temperature and the supporting buffer were considered. $\mathrm{Fe}^{2+/ 3+}$ (hydroxyethylethylenediaminetriacetic acid) (HEDTA) was identified as a suitable redox candidate due to its high solubility $\left(>1 \mathrm{~mol} \mathrm{~kg}^{-1}\right)$ in a near-neutral $\mathrm{pH}$ range from 4 to 6 . In the optimized conditions with a malonate buffer, the diffusion-limiting current density could reach over $100 \mathrm{~mA} \mathrm{~cm}^{-2}$ on a glassy carbon rotating disk electrode. The detailed 
insight presented in this paper will help to design an efficient electrochemical system for redox-mediated energy storage/conversion.

Keywords: Electrochemistry, redox mediator, Fe complex, HEDTA, energy conversion 


\section{INTRODUCTION}

The electrochemical production of hydrogen has gained tremendous attention to

store intermittent renewable energy sources, such as solar and wind power. A lot of

effort has been devoted to developing water-splitting devices in which a hydrogen

evolution reaction (HER) takes place on a cathode and an oxygen evolution reaction

(OER) happens on an anode to decrease the required voltage, improve stability, and

develop ubiquitous-element electrodes. The components that determine the required

voltage for water splitting are thermodynamics $(1.23 \mathrm{~V})$, kinetic overpotential on the

electrocatalyst, diffusion overpotential and Ohmic loss. Tandem- or series-connected

solar cells are, therefore, required to achieve enough voltage ${ }^{1-3}$ when solar energy is

used as a renewable feedstock. It is well known that the kinetics of the OER requires

additional overpotential compared to the HER and that the overpotential for OER

required to achieve $10 \mathrm{~mA} \mathrm{~cm}^{-2}$ is approximately $200 \mathrm{mV}$ with finely tuned

electrocatalysts on high surface area substrates immersed in a highly alkaline aqueous

solution at ambient temperature. ${ }^{4,5}$ In fact, to achieve electrochemical hydrogen

evolution, anodic reaction is not limited to the OER. For example, in the commercialized 
chloro-alkaline process, chloride ion is oxidized to chlorine while hydrogen evolves on the cathode. Alternative anodic reactions during the HER have been proposed in the literature, such as oxidative upgrading of biomass feedstock ${ }^{6-8}$ and production of oxidizing agents like hydrogen peroxide or peroxydisulfate anion. ${ }^{9-11}$ In this paper, we discuss oxidation of soluble redox species, which can potentially serve as redox mediators for successive homogeneous reactions. By choice, some redox electrochemical reactions do not require adsorption on electrode materials due to its outer sphere electron transfer nature. In such cases, fast kinetics can be achieved, especially in contrast to that of the electrocatalytic OER. Since adsorption on electrocatalysts is not involved during electron transfer, non-noble metals and earthabundant materials are applicable for electrodes, such as carbon, steel and nickel. Redox potential can be tunable by choice with versatile options to combine with a variety of output voltage originating from renewable energy sources.

Redox species oxidized on an anode can be regenerated via various homogeneous reactions; for example, the oxidation of hydrogen sulfide (or more 
specifically sulfide ions). Hydrogen sulfide is a by-product (often waste) from wells of crude oil and natural gas, which is essential to be adequately treated. The Clauss process is commonly applied to convert toxic hydrogen sulfide to sulfur and water (Eq. 1).

$$
2 \mathrm{H}_{2} \mathrm{~S}+\mathrm{O}_{2} \rightarrow 2 \mathrm{~S}+2 \mathrm{H}_{2} \mathrm{O}
$$

As an alternative commercialized technique, redox chemistry in liquid phase is applied for the treatment of hydrogen sulfide (Eq. 2).

$$
\mathrm{H}_{2} \mathrm{~S}+2 \mathrm{Ox} \rightarrow \mathrm{S}+2 \mathrm{H}^{+}+2 \mathrm{Red}(2)
$$

where Ox and Red denote the oxidized and reduced redox species, respectively. The redox potential must be positive enough compared to the oxidation potential of the hydrogen sulfide. Iron-complexes with aminopolycarboxylic acid, such as ethylenediaminetetraacetic acid (EDTA), nitrilotriacetic acid (NTA), and hydroxyethylethylenediaminetriacetic acid (HEDTA) are introduced to Sulferox process and LO-CAT process while anthraquinone-based redox is applied for the Stretford 
process. ${ }^{12,13}$ The reduced redox is subsequently re-oxidized by bubbling oxygen (Eq. 3)

33

$$
\mathrm{Red}+\frac{1}{4} \mathrm{O}_{2}+\frac{1}{2} \mathrm{H}_{2} \mathrm{O} \rightarrow \mathrm{Ox}+\mathrm{OH}^{-}
$$

The overall reaction from Eq. $\mathrm{H}_{2} \mathrm{~S}+2 \mathrm{Ox} \rightarrow \mathrm{S}+2 \mathrm{H}^{+}+2 \mathrm{Red}$

(2) and Eq.

Red $+\frac{1}{4} \mathrm{O}_{2}+\frac{1}{2} \mathrm{H}_{2} \mathrm{O} \rightarrow \mathrm{Ox}+\mathrm{OH}^{-}$(3) during the process is shown in Eq. 4, which is the same as the Clauss process.

$$
2 \mathrm{H}_{2} \mathrm{~S}+\mathrm{O}_{2} \rightarrow 2 \mathrm{~S}+2 \mathrm{H}_{2} \mathrm{O}
$$

In this process, the redox species are not consumed and serve as an electron mediator between the sulfide and oxygen.

Instead of bubbling oxygen, redox species can be electrochemically re-oxidized

on the anode (Eq. 5) while producing hydrogen on the cathode (Eq. 6). 


$$
\begin{aligned}
& \mathrm{Red} \rightarrow \mathrm{Ox}+\mathrm{e}^{-} \\
& 2 \mathrm{H}^{+}+2 \mathrm{e}^{-} \rightarrow 2 \mathrm{H}_{2}
\end{aligned}
$$

By combining Eq. $\mathrm{H}_{2} \mathrm{~S}+2 \mathrm{Ox} \rightarrow \mathrm{S}+2 \mathrm{H}^{+}+2 \mathrm{Red} \quad$ (2) $\mathrm{Red} \rightarrow \mathrm{Ox}+\mathrm{e}^{-} \quad$ (5), and

$2 \mathrm{H}^{+}+2 \mathrm{e}^{-} \rightarrow 2 \mathrm{H}_{2} \quad$ (6), the overall reaction becomes Eq. 7, which is the splitting of hydrogen sulfide to hydrogen and sulfur.

$$
\mathrm{H}_{2} \mathrm{~S} \rightarrow 2 \mathrm{H}_{2}+\mathrm{S}
$$

Hydrogen sulfide has a great advantage as feedstock of hydrogen compared to water due to its thermodynamics. The redox potential of sulfide to sulfur is approximately 0.14 $V$ relative to the reversible hydrogen electrode (RHE),${ }^{14}$ which indicates that single silicon solar cells can be potentially applied to produce hydrogen. Since the direct oxidation of sulfide ion on an anode may cause precipitation of insulating solid sulfur on the surface of anode ${ }^{15,16}$, the redox-mediated process is an attractive approach. A variety of redox ions, such as Fe-based redox, iodide, vanadate and heteropoly molybdophosphate, are investigated. ${ }^{17-21}$ 
The present work provides detailed insight on the thermodynamics and kinetics

for potential candidates of Fe redox species, Fe-EDTA and Fe-HEDTA in addition to anthraquinone-2,6-disulfonate (AQDS) as an organic form. From a thermodynamic point of view, a near-neutral $\mathrm{pH}$ was effectively selected to provide suitable voltage range, but it requires the use of supporting buffers to minimize local $\mathrm{pH}$ shift during proton-coupled electron transfer reactions. Near-neutral pH also has an advantage compared to acidic conditions to provide potential candidates for a non-noble metal cathode for HER.

Although the presence of redox couple can potentially hinder HER on cathode, selective HER can be achieved by incorporation of ion exchange membranes or membrane coated electrodes to prevent side reactions. ${ }^{22-25}$ Due to the highly reversible kinetics of redox species, mass transport represents a major contribution to the current response. Fe-HEDTA has a high solubility $\left(1 \mathrm{~mol} \mathrm{~kg}^{-1}\right)$, which helps to overcome the diffusion problem. In addition, temperature and the supporting buffer were also examined to improve the diffusion-limitation of redox species. 


\section{MATERIALS AND METHODS}

Materials. All chemicals were purchased with the following purities: $\mathrm{KOH}(99.99 \%$,

Sigma-Aldrich, St. Louis, USA), $\mathrm{NaOH}\left(99.99 \%\right.$, Sigma-Aldrich), $\mathrm{FeSO}_{4} \cdot 7 \mathrm{H}_{2} \mathrm{O}(99.0 \%$,

Sigma-Aldrich), $\mathrm{Fe}_{2}\left(\mathrm{SO}_{4}\right)_{3}$ hydrate (Sigma-Aldrich), $\mathrm{FeCl}_{3} \cdot 6 \mathrm{H}_{2} \mathrm{O}(\geq 99 \%$, Sigma-

Aldrich), HEDTA-Na 3 ( $\geq 99 \%$, Fisher Scientific, Pittsburgh, USA), HEDTA-Fe (99\%,

Phygenera, Langenberg, Germany), $\mathrm{K}_{3}\left[\mathrm{Fe}(\mathrm{CN})_{6}\right]\left(>99.9 \%\right.$, Sigma-Aldrich), $\mathrm{K}_{4}\left[\mathrm{Fe}(\mathrm{CN})_{6}\right]$

(99.5\%, Sigma-Aldrich), AQDS (>97\%, TGI), $\mathrm{HOC}(\mathrm{COONa})\left(\mathrm{CH}_{2} \mathrm{COONa}\right)_{2} \cdot 2 \mathrm{H}_{2} \mathrm{O}(\geq$

99.0\%, Sigma-Aldrich), $\mathrm{C}_{3} \mathrm{H}_{4} \mathrm{O}_{4}\left(99 \%\right.$, Alfa Aesar, Ward Hill, USA), $\mathrm{C}_{6} \mathrm{H}_{8} \mathrm{O}_{7}(100.7 \%$,

Fisher Scientific). The water used in all experiments was obtained from a Milli-Q Integral

system (Millipore, Burlington, USA) with a resistivity of $18.2 \mathrm{M} \Omega \mathrm{cm}$. The $\mathrm{pH}$ of

electrolyte solutions was adjusted using $\mathrm{H}_{2} \mathrm{SO}_{4}$ (99.999\%, Sigma-Aldrich), $8 \mathrm{M} \mathrm{NaOH}$

solution (Sigma-Aldrich), or KOH. A carbon felt (AvCarb G100 Soft Graphite Battery

Felt, thickness $3.2 \mathrm{~mm}$, Fuel Cell Store, College Station, USA) was pretreated in air at

$773 \mathrm{~K}$ for $5 \mathrm{~h}$ to make it hydrophilic. ${ }^{26}$ 
Electrochemistry. Electrochemical measurements were achieved using a BioLogic

VMP3 potentiostat (Seyssinet-Pariset, France). Rotating disk electrodes (RDEs, $3 \mathrm{~mm}$

diameter, ALS CO., Ltd, Tokyo, Japan) of glassy carbon and polycrystalline Pt were

used as working electrodes. Carbon paper or Pt wire was employed as counter

electrodes. Before each measurement, the disk electrodes were first polished with $1 \mu \mathrm{m}$

of diamond and then with $0.05 \mu \mathrm{m}$ of alumina followed by electrochemical cleaning in a

$1 \mathrm{M} \mathrm{HClO}_{4}$ solution between -0.9 and $1.7 \mathrm{~V}$ vs. SHE (standard hydrogen electrode) for glassy carbon or between -0.02 and $1.8 \mathrm{~V}$ vs. SHE for $\mathrm{Pt} . \mathrm{Ag} / \mathrm{AgCl}$ (saturated $\mathrm{KCl}$ )

(ALS CO., Ltd) was used as the reference electrode. The potentials were reported with $i R_{u}$-correction unless otherwise specified. Uncompensated resistance $R_{u}$ was measured by impedance spectroscopy (100 mHz $-10 \mathrm{kHz}, 10 \mathrm{mV}$ amplitude). Before and during all measurements, $\operatorname{Ar}(99.999 \%)$ was continuously supplied to the electrochemical cell. Because reduced AQDS is not commercially available, AQDS was electrochemically reduced using a carbon felt cathode at $0 \mathrm{~V}$ vs. RHE in a two compartment cell separated by Nafion 212 membrane (Fuel Cell Store) under Ar atmosphere assuming a reduction with 1.5 electron per molecule. ${ }^{27}$ The kinematic viscosity and density of the 
electrolyte solutions were obtained using viscometer tubes (cell constants: 0.003259

and $0.009167 \mathrm{~mm}^{2} \mathrm{~s}^{-2}$, Fisher Scientific) and a density meter (DM40, METTLER

TOLEDO, Columbus, USA), respectively.

\section{RESULTS AND DISCUSSION}

Thermodynamics of redox species. The redox potential of the $0.1 \mathrm{M}$ redox species ${ }^{28-30}$

from the standard hydrogen electrode (SHE) is compared to the potential of $\mathrm{S}^{2-10}$

species $^{14}$ and HER/hydrogen oxidation reaction (HOR) in Figure 1a. 


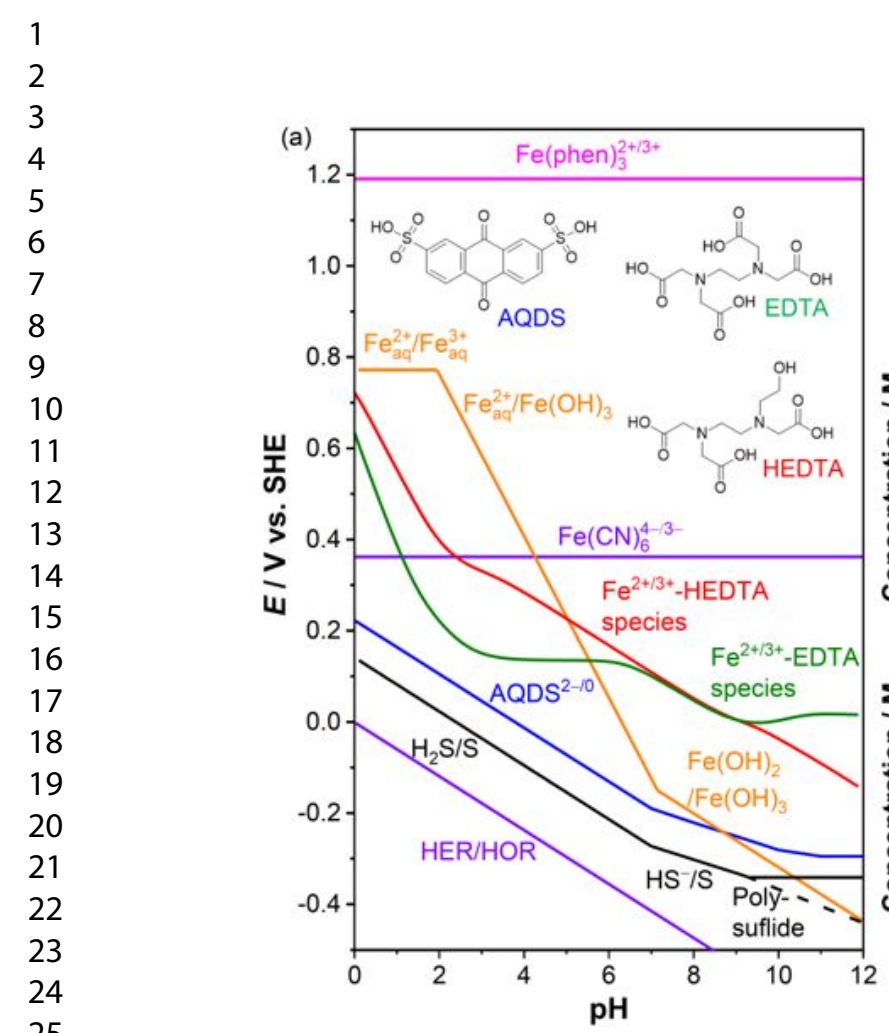

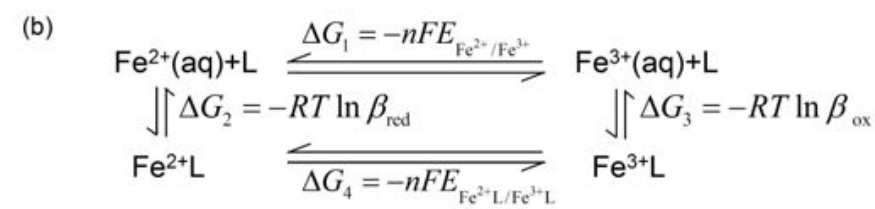
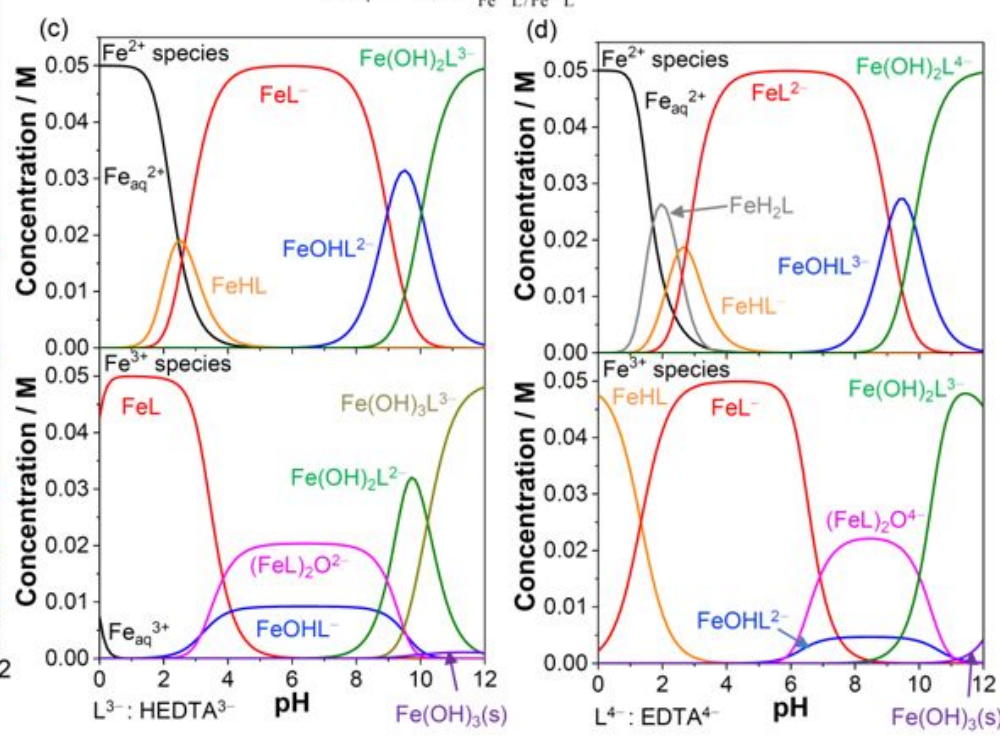

Figure 1. (a) Potential-pH diagram of total $0.1 \mathrm{M}$ of $\mathrm{Fe}^{2+/ 3+}$-based redox species $(50 \%$

oxidized and $50 \%$ reduced) with the $S^{2-10}$ species and the HER/HOR. The redox

potential of $1 \mathrm{mM}$ of AQDS was reproduced from the literature. ${ }^{28}(\mathrm{~b})$ Thermochemical

cycle describing the change in Gibbs free energy of the metal complex. (c) (d)

Speciation distribution diagram of $\mathrm{Fe}^{2+}$ and $\mathrm{Fe}^{3+}$ in the solution containing $0.05 \mathrm{M} \mathrm{Fe}^{2+}$,

$0.05 \mathrm{M} \mathrm{Fe}^{3+}$, and (c) $0.1 \mathrm{M} \mathrm{HEDTA}^{3-}$ and (d) $0.1 \mathrm{M} \mathrm{EDTA}^{4-}$ obtained from the HySS

program. The formation constants are shown in Table S1. 
The redox potential of the iron-based complex can be described by the standard potential of the $\mathrm{Fe}_{\mathrm{aq}}{ }^{2+3+}$ ion, the corresponding formation constant of the metal complex $\left(\beta_{\mathrm{ox}}\right.$ and $\left.\beta_{\mathrm{Red}}\right)$ and the activity of the responsible species $\left(a_{\mathrm{ox}}\right.$ and $\left.a_{\mathrm{red}}\right),{ }^{31,32}$ as shown in Eq. 8. 


$$
E=E_{\mathrm{Fe}_{a q}^{2+} / \mathrm{Fe}_{a q}^{3+}}-\frac{R T}{n} \times \ln \frac{\beta_{\mathrm{ox}}}{\beta_{\mathrm{red}}}+\frac{R T}{n} \times \ln \frac{a_{\mathrm{ox}}}{a_{\mathrm{red}}}
$$

where $n$ denotes the number of charges transferred for the corresponding redox reaction, and $R$ and $T$ represent the universal gas constant and temperature, respectively. The first two terms in the right side of the equation are derived from the thermochemical cycle shown in Figure $1 \mathrm{~b}$ where the Gibbs free energy of the metal complex redox couple $\left(\Delta G_{4}\right)$ can be obtained from the corresponding Gibbs free energy of the metal redox couple $\left(\Delta G_{1}\right)$ and the formation of the metal complex $\left(\Delta G_{2}\right.$ and $\left.\Delta G_{3}\right)$. The Gibbs free energy change is independent of the reaction pathway, which gives Eq. 9.

$$
\Delta G_{1}+\Delta G_{3}=\Delta G_{2}+\Delta G_{4}
$$

Therefore, the Gibbs free energy change of the redox reaction for the metal complex can be determined as shown in Eq. 10.

$$
\Delta G_{4}=\Delta G_{1}-\Delta G_{2}+\Delta G_{3}
$$


The last term in Eq. 8 is to compensate for the activities of the oxidized and reduced species following the Nernst equation. The speciation distribution of the redox couple is obtained from the corresponding equilibrium constants. The distribution of the $\mathrm{Fe}^{2+/ 3+}-$ HEDTA and Fe ${ }^{2+/ 3+}$-EDTA species is shown in Figure $1 \mathrm{c}$ and $1 \mathrm{~d}$, respectively and the corresponding equilibrium constants ${ }^{31,33-36}$ are shown in Table S1. As can be seen from Eq. 8, the formation constants of the metal complex can shift the redox potential considerably from the potential of the free $\mathrm{Fe}_{\mathrm{aq}}{ }^{2+/ 3+}$ ion couple. EDTA derivatives have a negatively-charged oxygen in their carboxylic group that stabilizes the $\mathrm{Fe}^{3+}$ more than the $\mathrm{Fe}^{2+}$, making the reduction of ferric ion more energetically-demanding, while phenanthroline serves as a $\pi$-acceptor that delocalizes the electron from $\mathrm{Fe}^{2+}$ resulting in a positive shift of redox potential from the $\mathrm{Fe}_{\mathrm{aq}}{ }^{2+/ 3+}$ couple. The potential-pH diagram shows that all of the redox species shown can thermodynamically oxidize hydrogen sulfide to sulfur. The following order is the requirement of thermodynamics to demonstrate the HER with the oxidation of the redox in the neutral $\mathrm{pH}$ range (4-7).

$$
\text { AQDS }<\text { Fe-EDTA }<\text { Fe-HEDTA }<\text { Fe }(\mathrm{CN})_{6}
$$


Although EDTA and HEDTA have similar structures, as shown in Figure 1a, different slopes were observed in the $\mathrm{pH}$ range from 3 to7. Fe-EDTA has $\mathrm{pH}$-independent redox potential in this range because proton transfer is not required in the redox reaction for the predominant species shown in Figure 1d. Therefore, the thermodynamic voltage for the HER and oxidation of Fe-EDTA is $\mathrm{pH}-$ dependent and slightly acid conditions $(\mathrm{pH} 3-$ 4) are thermodynamically favorable. On the other hand, Fe-HEDTA had a slope of 59 $\mathrm{mV} \mathrm{pH}^{-1}$ because proton transfer was also involved in the reaction. The thermodynamic voltage required for the HER and oxidation of Fe-HEDTA is constant to be $\sim 0.50 \mathrm{~V}$ in a wide range within neutral region from $\mathrm{pH} 3$ to 8 (Figure 1). This constant value can be an advantage to design the overall process which is not influenced by the $\mathrm{pH}$, including the choice of cathode material and the subsequent homogeneous reaction with $\mathrm{H}_{2} \mathrm{~S}$. On the other hand, Fe-EDTA exhibits small but various voltages $(\sim 0.32-0.50 \mathrm{~V})$ in the same $\mathrm{pH}$ range, which requires additional care of the operation. It should also be noted that these Fe-redox reactions involve the proton-coupled electron transfer reactions; i.e., an additional voltage loss due to the local pH shift (concentration overpotential) needs to be minimized upon the steady state electrochemical operation. In this context, a use of 
supporting buffer is essential to minimize the local pH shift, which will be discussed later. While the oxidation of the sulfide ion to sulfur is the primary target in this paper, the tunability of the redox potential through the formation of a metal complex allows for various applications towards homogeneous reactions and energy storage.

Electrochemical measurements of redox species. The cyclic voltammograms of candidate redox (Fe-EDTA, Fe-HEDTA, AQDS, and $\left.\mathrm{Fe}(\mathrm{CN})_{6}\right)$ were measured using a glassy carbon rotating disk electrode, as shown in Figure $2 \mathrm{a}$ and the anodic current at $900 \mathrm{rpm}$ are compared in Figure 2c. A total $0.1 \mathrm{~mol} \mathrm{~kg}^{-1}$ of redox species, $50 \%$ in a reduced form and $50 \%$ in an oxidized form, were introduced into a $0.5 \mathrm{~mol} \mathrm{~kg}^{-1}$ citratebuffered solution at $\mathrm{pH} 5$.

First, the onset potentials of the redox species appeared in the order below.

$$
\mathrm{AQDS}<\mathrm{Fe}-\mathrm{EDTA} \approx \mathrm{Fe}-\mathrm{HEDTA}<\mathrm{Fe}(\mathrm{CN})_{6}
$$

The estimated potential for Fe-EDTA ( $0.13 \mathrm{~V}$ vs. SHE in Figure $1 \mathrm{a})$ agreed well with the measured onset potential (approximately $0.14 \mathrm{~V}$ vs. SHE, $0.44 \mathrm{~V}$ vs. RHE at pH 5). 
In contrast, for Fe-HEDTA, there was a slight difference between the estimated and the measured potentials $(\sim 0.1 \mathrm{~V})$. In this estimation, the activity coefficients of the oxidized and reduced species are assumed to be in unity in the potential-pH diagram. Relatively dense redox solutions $\left(0.1 \mathrm{~mol} \mathrm{~kg}^{-1}\right)$ used may cause the strong ion interaction, such as oligomerized $\mathrm{Fe}^{3+}$-HEDTA formed at $\mathrm{pH}$ 5, alkali ions, and buffer ions. Indeed, a potential shift of more than $100 \mathrm{mV}$ from the standard potential for the $\mathrm{Fe}(\mathrm{CN})_{6}{ }^{4-3-}$ redox couple was reported due to an association with alkali cations; ${ }^{37-39}$ e.g., the association constants with potassium cation are reported to be $10^{1.46}$ and $10^{2.35}$ for $\mathrm{Fe}(\mathrm{CN})_{6}{ }^{3-}$ and $\mathrm{Fe}(\mathrm{CN})_{6}{ }^{4-}$, respectively. ${ }^{40}$ The lower formation constant of $\mathrm{Fe}^{3+}-\mathrm{HEDTA}$ $(\log \beta=20)$ than that of $\mathrm{Fe}^{3+}-\mathrm{EDTA}(\log \beta=25)($ Table S1) might cause additional complex formation with citrate, which may in turn lead to the potential shift. 
(a)

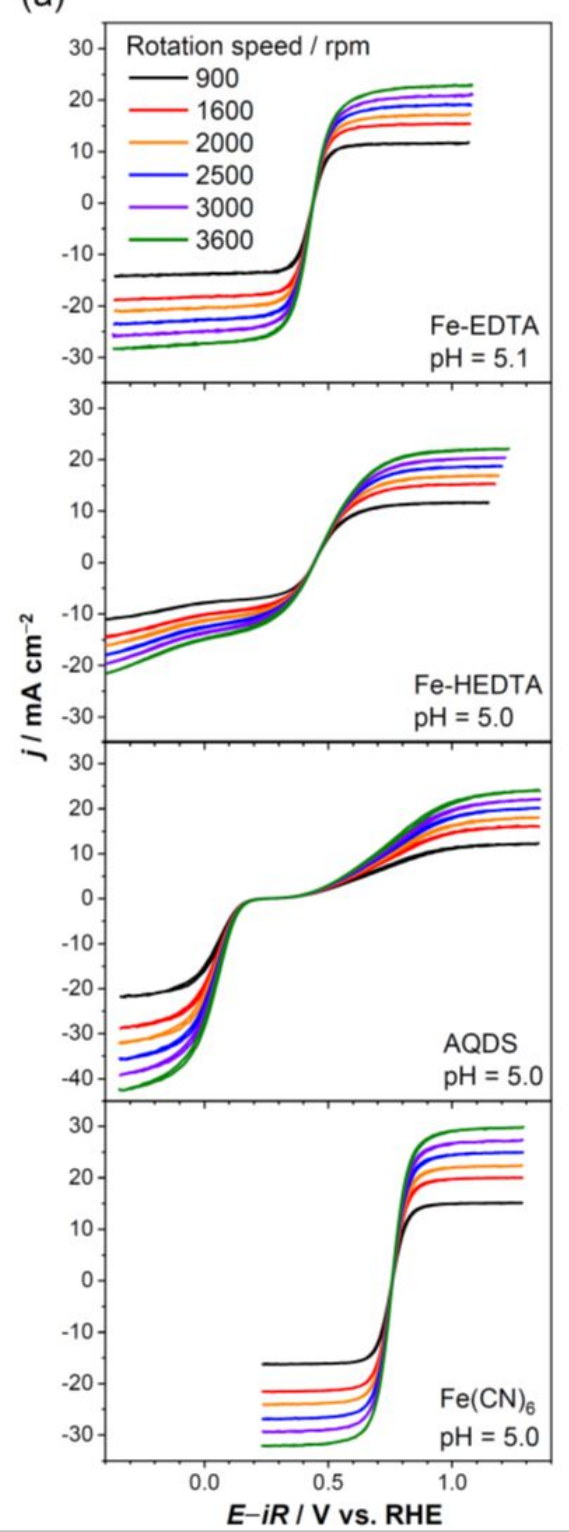

(b)

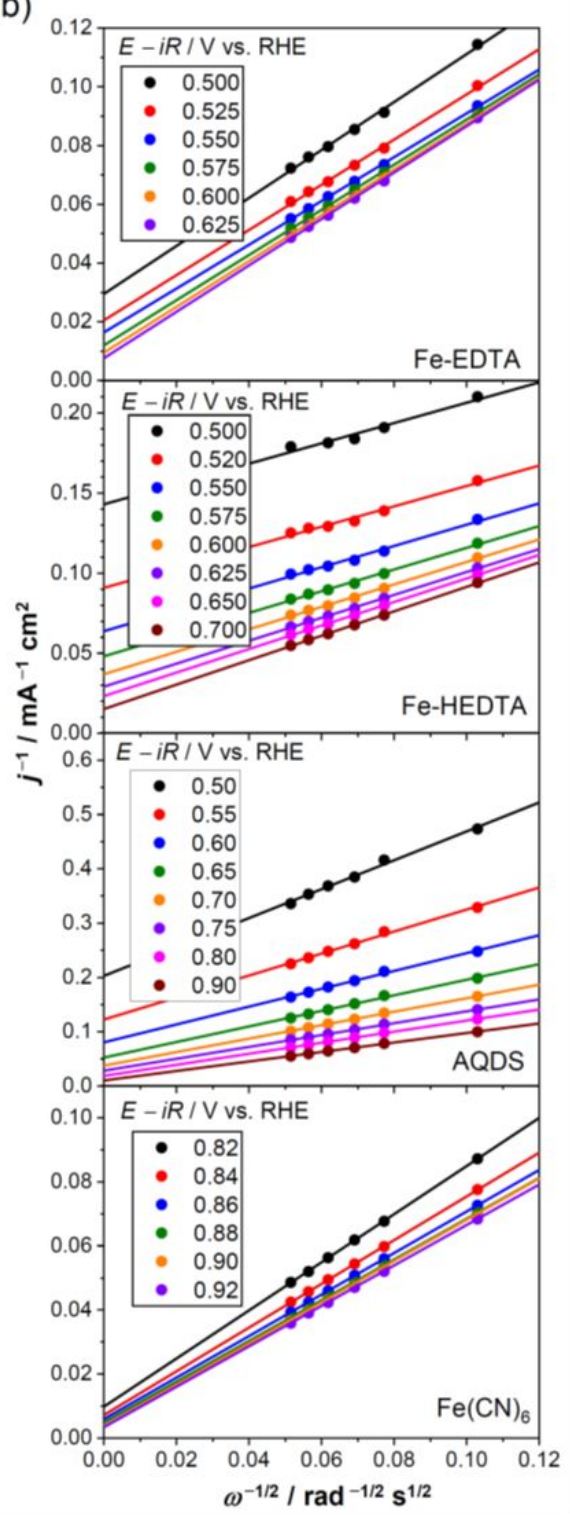

(c)

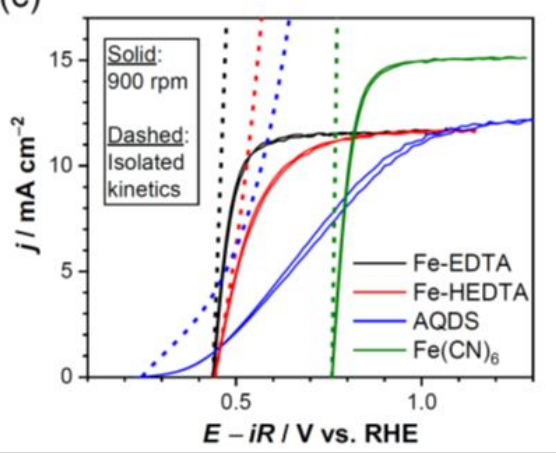

(d)

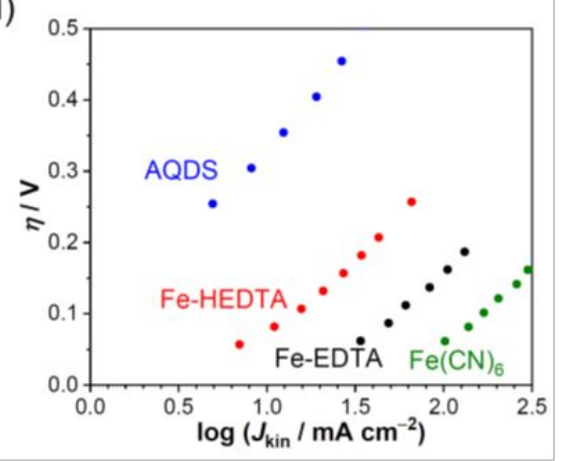


Figure 2. (a) Cyclic voltammograms measured using a glassy carbon rotating disk electrode in a solution containing a total of $0.1 \mathrm{~mol} \mathrm{~kg}^{-1}$ redox species (Fe-EDTA, FeHEDTA, AQDS or $\left.\mathrm{Fe}(\mathrm{CN})_{6}\right)$ with $0.5 \mathrm{~mol} \mathrm{~kg}^{-1}$ citrate buffer. Redox solutions have $50 \%$ reduced species and $50 \%$ oxidized ones. $\left(50 \mathrm{mV} \mathrm{s}^{-1}, 298 \mathrm{~K}\right)$. (b) Corresponding Koutecký-Levich plot. (c) Anodic current at 900 rpm shown in Figure 2a with the isolated kinetic current obtained from the Koutecký-Levich plot. (d) Tafel plot of kinetic current.

The cyclic voltammograms in Figure 2a clearly show the anodic and cathodic diffusionlimiting current of redox species. For Fe-HEDTA, the second step reduction was observed at more negative potential than $0 \mathrm{~V}$ vs. RHE. For Fe-HEDTA, the second step reduction was observed at more negative potential than $0 \mathrm{~V}$ vs. RHE. In the cyclic voltammogram of analogous redox, V-HEDTA, sequential reduction peaks were accordingly assigned to the reduction of the monomer and dimer species, respectively, considering the homogeneous dissociation rate limitation. ${ }^{41}$ In Figure 2a, the reduction of the monomer Fe-HEDTA takes place at $0.44 \mathrm{~V}$ vs. RHE while the dimer species started to be reduced at $0 \mathrm{~V}$ vs. RHE. The cyclic voltammograms in Figure Error! Reference source not found. 
show that the current of AQDS increased slowly, while the one for $\mathrm{Fe}(\mathrm{CN})_{6}$ shows a sharp

increase. As a diffusion-limiting current was observed, the observed current-potential relationship contains contributions from diffusion and kinetics on the electrode. The Koutecký-Levich analysis was applied to isolate their contributions following Eq. 11 and the corresponding Koutecký-Levich plots are shown in Figure 2b,

$$
\frac{1}{j}=\frac{1}{j_{\text {kin }}}+\frac{1}{j_{\text {lim }}}
$$

where $j, j_{\text {kin }}$, and $j_{\text {im }}$ represent the measured current density, kinetic current density on the electrode, and diffusion-limiting current density at a given rotation speed, respectively. The diffusion-limiting current density is given by the Levich equation (Eq. 12).

$$
j_{\mathrm{lim}}=0.62 n F \gamma c D^{2 / 3} v^{-1 / 6} \varpi^{1 / 2}
$$

where $n$ is the number of required electrons, $F$ is Faradaic constant, $\gamma$ is the activity coefficient, $c$ is the concentration of redox, $D$ is the diffusion coefficient, $v$ is the kinematic viscosity, and $\omega$ is the rotation speed. Tafel plots of the obtained kinetic 
current densities are shown in Figure $2 \mathrm{~d}$, which clearly shows that $\mathrm{Fe}(\mathrm{CN})_{6}$ has facile kinetics toward electrochemical oxidation while AQDS has poor kinetics. Due to the considerable differences in their structure and charge, a fair comparison of the reaction rate is difficult among these redox species. In this paper, the comparison is limited between Fe-EDTA and Fe-HEDTA, which have similar structures. According to the Marcus theory, ${ }^{42,43}$ the activation free energy at standard potential $\left(\Delta G_{0}^{*}\right)$ is determined by the reorganization energy $(\lambda)$ as shown in Eq. 13 .

$$
\Delta G_{0}^{*}=\frac{\lambda}{4}=\frac{\lambda_{i}+\lambda_{o}}{4}
$$

where $\lambda_{i}$ and $\lambda_{0}$ denote the inner and outer reorganization energy, respectively. The inner reorganization energy represents the vibrational contribution of the structure while the outer reorganization comes from the surrounding dipole solvent. The predominant reactions at pH 5 are shown in Eq. 14 and 15. 


$$
\begin{aligned}
& \mathrm{Fe}^{2+}-\mathrm{EDTA}^{2-} \rightarrow \mathrm{Fe}^{3+}-\mathrm{EDTA}^{-}+\mathrm{e}^{-} \\
& \mathrm{Fe}^{2+}-\mathrm{HEDTA}^{-}+\mathrm{H}_{2} \mathrm{O} \rightarrow \mathrm{Fe}^{3+}-(\mathrm{OH}) \mathrm{HEDTA}^{-}+\mathrm{H}^{+}+\mathrm{e}^{-}
\end{aligned}
$$

While Fe-EDTA is a simple electron transfer reaction, Fe-HEDTA shows proton-coupled electron transfer. Therefore, the inner reorganization energy of Fe-HEDTA is expected to be higher than that of Fe-EDTA, which might have resulted in the poor kinetics of FeHEDTA compared to Fe-EDTA.

Even though the potential to reach $10 \mathrm{~mA} \mathrm{~cm}^{-2}$ was $0.5 \mathrm{~V}$ vs. RHE at $900 \mathrm{rpm}$ in the presence of Fe-EDTA, which is the most negative among the redox species investigated, the diffusion-limiting current is only $11 \mathrm{~mA} \mathrm{~cm}^{-2}$ even with vigorous rotation (900 rpm) at room temperature. Using a glassy-carbon electrode, Figure $2 \mathrm{c}$ also shows isolated kinetic current densities. From this figure, it is clear that the diffusion overpotential, which is the difference between kinetic overpotential and measured overpotential, plays a major role as the current increases. This diffusion overpotential is expected to increase when it is operated in static or practical operational conditions, suggesting that the engineering of the electrolyte rather than the electrode material is 
the key to improvement. The diffusion overpotential is determined by the diffusion-

limiting current, according to Fick's law shown in Eq. 16.

$$
J_{\lim }=n F D \frac{\partial a}{\partial x}(16)
$$

where $n$ is the required number of redox reactions, $F$ is the Faradaic constant, $D$ is the diffusion coefficient, $a$ is the activity in the bulk solution, and $x$ is the thickness of the diffusion layer. Increasing the concentration of the redox species is a simple approach to improve the diffusion-limiting current for practical applications. Cyclic voltammetry and chronoamperometry at the potential where the diffusion-limiting current was observed were performed with a variety of concentrations of redox solutions containing only reduced species ( $\mathrm{Fe}^{2+}-$ EDTA and $\left.\mathrm{Fe}^{3+}-\mathrm{HEDTA}\right)$, as shown in Figure $3 \mathrm{a}$ and $3 \mathrm{~b}$, respectively. 
(a)

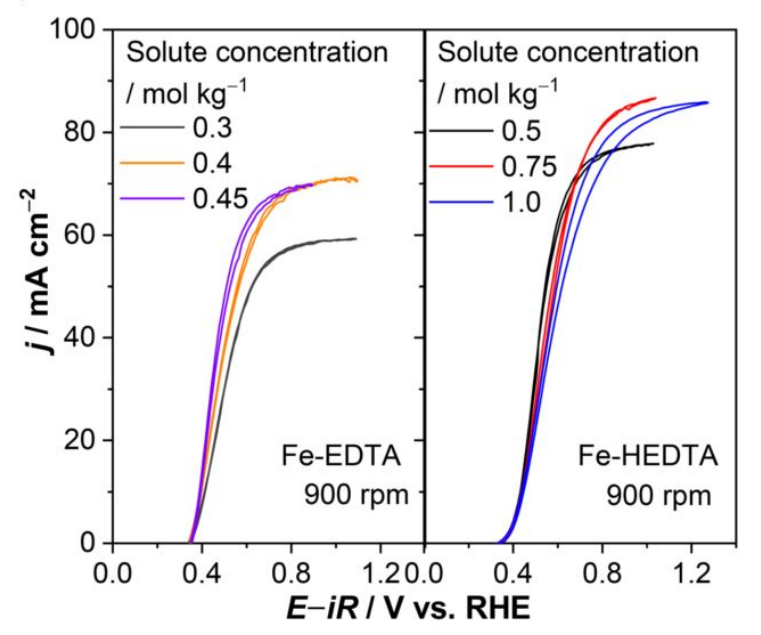

(b)

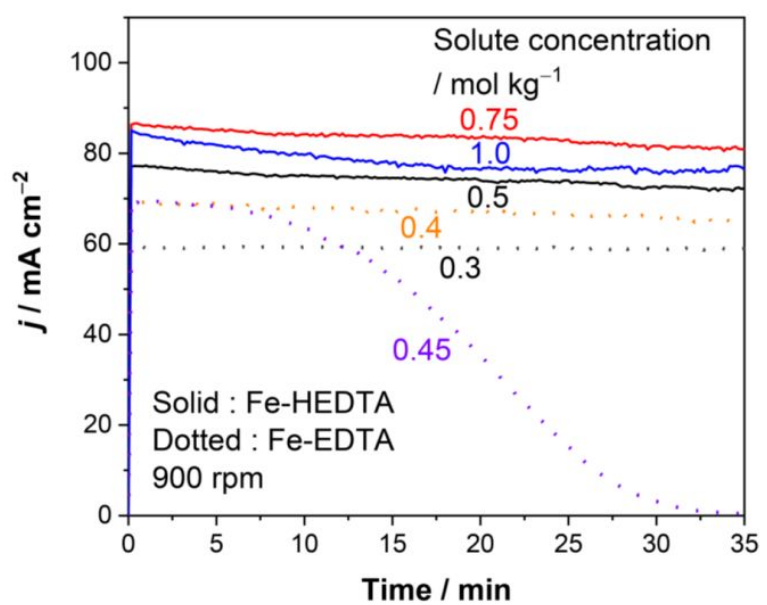

Figure 3. (a) Cyclic voltammograms measured using a glassy carbon rotating disk electrode in a solution containing $\mathrm{Fe}^{2+}$-EDTA or $\mathrm{Fe}^{2+}$-HEDTA with $0.5 \mathrm{~mol} \mathrm{~kg}^{-1}$ citrate buffer ( $\mathrm{pH}=5, \mathrm{Ar}, 50 \mathrm{mV} \mathrm{s}^{-1}, 900 \mathrm{rpm}, 298 \mathrm{~K}$ ). (b) Corresponding l-t profile measured at the potential where the diffusion-limiting current was observed.

Up to $0.4 \mathrm{~mol} \mathrm{~kg}^{-1}$ of $\mathrm{Fe}^{2+}-\mathrm{EDTA}$, the diffusion-limiting current density increased to $70 \mathrm{~mA} \mathrm{~cm}^{-2}$ and this is higher than that observed in Figure $3 a$ suggesting that the concentration of reactant plays an important role, as shown in Eq. 16. When the concentration of $\mathrm{Fe}^{2+}$-EDTA reached $0.45 \mathrm{~mol} \mathrm{~kg}^{-1}$, the diffusion-limiting current density did not change from that in $0.4 \mathrm{~mol} \mathrm{~kg}^{-1}$ (Figure 3a) and a considerable decay of the current density, which approached close to $0 \mathrm{~mA} \mathrm{~cm}^{-2}$, started to appear during 
chronoamperometry (Figure 3b). After the chronoamperometry in $0.45 \mathrm{~mol} \mathrm{~kg}^{-1}$ of $\mathrm{Fe}^{2+}-$

EDTA, precipitation was observed on the anode resulting in the disappearance of anodic current, which comes from less soluble Fe ${ }^{3+}$-EDTA $\left(<0.2 \mathrm{~mol} \mathrm{~kg}^{-1}\right)$. On the other hand, constant current density above $70 \mathrm{~mA} \mathrm{~cm}^{-2}$ was observed in the presence of $\mathrm{Fe}^{2+}$-HEDTA above $0.5 \mathrm{~mol} \mathrm{~kg}^{-1}$ that can exceed the diffusion-limiting current density of $\mathrm{Fe}^{2+}$-EDTA $\left(70 \mathrm{~mA} \mathrm{~cm}^{-2}\right.$ with $\left.0.4 \mathrm{~mol} \mathrm{~kg}^{-1}\right)$, as shown in Figure $3 \mathrm{~b}$. These results indicate that the solubility of both the oxidized and reduced redox species must be considered to determine the concentration of the redox solution. Noticeably, Fe-HEDTA showed sufficient solubility $\left(>1 \mathrm{~mol} \mathrm{~kg}^{-1}\right)$ regardless of the oxidation state of $\mathrm{Fe}$, which makes it possible to operate the proposed system at high concentrations. The diffusionlimiting current density did not increase when the concentration was increased from 0.75 to $1.0 \mathrm{~mol} \mathrm{~kg}^{-1}$. This could stem from the diffusion-limit of citrate buffer since the oxidation of Fe-HEDTA is proton-coupled electron transfer and the concentration of the buffer was limited to $0.5 \mathrm{~mol} \mathrm{~kg}^{-1}$, which is smaller than that of the redox species, in this series of measurements. Optimization of the supporting buffer is further discussed in the following section. The high solubility is likely associated with the soluble characteristics 
of the ligand itself, where the solubility of HEDTA-Na ${ }_{3}$ is $>2.5 \mathrm{~mol} \mathrm{~kg}^{-1}$ while that of EDTA-Na 2 is only $0.4 \mathrm{~mol} \mathrm{~kg}^{-1}$. It is interesting to note that the difference in the structure between these ligands is that one carboxylic functional group on EDTA is substituted with an alcohol group on HEDTA, as shown in Figure 1a. Although $\mathrm{Fe}(\mathrm{CN})_{6}$ is also well soluble $\left(\sim 0.4 \mathrm{~mol} \mathrm{~L}^{-1}\right)$ and proposed for redox flow batteries, ${ }^{44,45}$ the onset potential of Fe-HEDTA ( $0.43 \mathrm{~V}$ vs. RHE) appears more negative than that of $\mathrm{Fe}(\mathrm{CN})_{6}(0.75 \mathrm{~V}$ vs. $\mathrm{RHE}$ ) at $\mathrm{pH} 5$ as shown in Figure $2 \mathrm{c}$, which is a great advantage to reduce the overall cell voltage when HER is also performed on a cathode. Therefore, we identified FeHEDTA as a suitable candidate for this study because of the remarkable solubility, which helps to overcome diffusion issues, and $\mathrm{pH}$-independent thermodynamic voltage to perform redox oxidation and HER (approximately $0.43 \mathrm{~V}$ ) in a nearly neutral $\mathrm{pH}$ range (2-8). Further studies on Fe-HEDTA were performed in the following section under dense redox conditions.

Electrochemical measurements of dense Fe-HEDTA at various $\mathrm{pH}$. The redox potential estimated from the speciation distribution with different concentrations is shown as a 
solid line in Figure 4a assuming that the activity coefficients of Fe-HEDTA are one. The redox potential estimated based on the equilibrium constants shifted toward negative by increasing the concentration of Fe-HEDTA, likely due to an increase in the fraction of dimerized $\mathrm{Fe}^{3+}$-HEDTA, which has more negative standard potential compared to that of the monomer. The formal potential with a total of $1.0 \mathrm{~mol} \mathrm{~kg}^{-1} \mathrm{Fe}$-HEDTA was obtained by open circuit potential measurement at different $\mathrm{pH}$ by introducing $0.5 \mathrm{~mol}$ $\mathrm{kg}^{-1}$ of excess HEDTA as a buffer, which is also shown in Figure 4a as scattered points. The measured potential appeared more negative than the estimated potential, which was also observed with a total of $0.1 \mathrm{~kg}^{-1}$ redox shown in Figure 1a and 2c. 


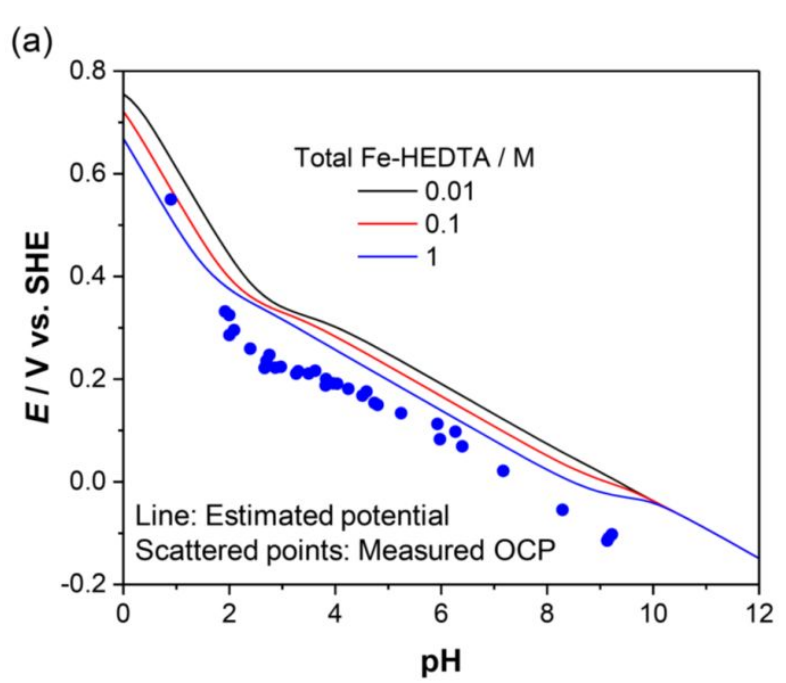

(b)
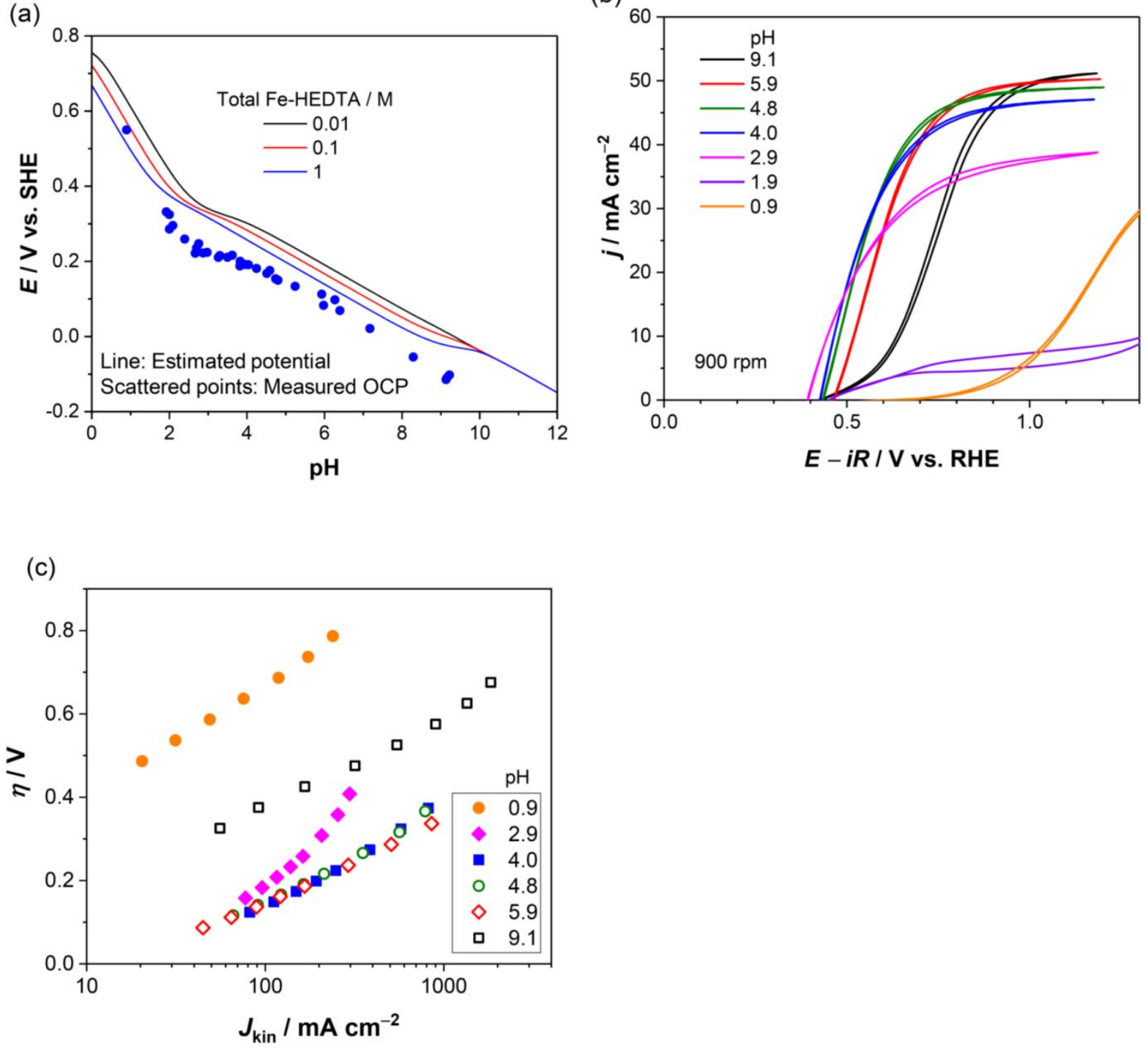

Figure 4. (a) Estimated redox potential obtained from speciation distribution with different concentrations of Fe-HEDTA and the open circuit potential (OCP) measured using a glassy carbon disk electrode in a solution containing $0.5 \mathrm{~mol} \mathrm{~kg}{ }^{-1}$ of $\mathrm{Fe}^{2+}-$ HEDTA, $0.5 \mathrm{~mol} \mathrm{~kg} \mathrm{kf}^{-1}$ of ${ }^{3+}$-HEDTA, and $0.5 \mathrm{~mol} \mathrm{~kg}^{-1}$ of HEDTA-Na $\mathrm{H}_{3}$ under $\mathrm{Ar}$ atmosphere. (b) Cyclic voltammograms measured using a glassy carbon rotating disk 
electrode in a redox solution (900 rpm, $50 \mathrm{mV} \mathrm{s}^{-1}, 298 \mathrm{~K}$ ). (c) Tafel plot of kinetic current obtained after the Koutecký-Levich analysis.

Electrochemical measurements at different $\mathrm{pH}$ were conducted using a glassy carbon rotating disk electrode and the cyclic voltammograms are shown in Figure 4b. Similar anodic diffusion-limiting current densities were observed in the $\mathrm{pH}$ range from 9 to 4 , while the diffusion-limiting current density decreased in the acidic $\mathrm{pH}$ range $(<3)$. The decreased diffusion-limiting current density in acid is ascribed to the formation of $\mathrm{Fe}_{\mathrm{aq}}{ }^{2+}$, which started to be oxidized at higher potentials as observed in the solution at $\mathrm{pH}$ 0.9. A Tafel plot of the kinetic current, which was obtained after Koutecký-Levich analysis, is shown in Figure 4c. This shows that superior kinetics were observed in $\mathrm{pH} 4$ - 6 while more acidic and alkaline conditions require higher overpotential. Non-linear behavior in the Tafel plot at $\mathrm{pH} 2.9$ may arise from the coexistence of various reduced species as shown in Figure 1c. Due to the local pH shift at high overpotential, the major reactant can switch to $\mathrm{FeHL}$ or $\mathrm{Fe}_{\mathrm{aq}}{ }^{2+}$, the reactions with which require additional 
overpotential, as in the case of the reaction at $\mathrm{pH} 0.9$ in Figure 4c. The $\mathrm{pH}$ dependence

of the kinetics was also investigated on a Pt rotating disk electrode (Figure S1).

Although approximately $3-6$-fold higher kinetic current was observed on the $\mathrm{Pt}$

compared to the glassy carbon electrode in the $\mathrm{pH}$ range investigated, similar $\mathrm{pH}$ -

dependence was also observed on the $\mathrm{Pt}$, which suggests that the obtained $\mathrm{pH}$ -

dependence came from the redox species itself in the electrolyte rather than the surface

nature of the electrode materials. Under acidic conditions, the $\mathrm{Fe}^{2+}$ species starts to

form $\mathrm{Fe}_{\mathrm{aq}}{ }^{2+}$ or neutral $\mathrm{Fe}(\mathbb{I}) \mathrm{HL}$. Obviously, the oxidation of $\mathrm{Fe}_{\mathrm{aq}}{ }^{2+}$ requires higher inner

reorganization energy through the formation of $\mathrm{Fe}(\mathbb{I I}) \mathrm{L}$ (Eq. 17) compared to the

reaction at medium $\mathrm{pH}$ (Eq. 15).

$$
\mathrm{Fe}^{2+}+\mathrm{HEDTA}^{3-} \rightarrow \mathrm{Fe}^{3+}-\text { HEDTA }+\mathrm{e}^{-}
$$

The oxidation of neutral $\mathrm{Fe}(\mathbb{I}) \mathrm{HL}$ is anticipated to require more outer reorganization energy compared to the negatively charged $\mathrm{Fe}(\mathrm{II}) \mathrm{L}^{-}$because negatively charged species can form a larger solvation shell through the polarization. Although more alkaline conditions $(\mathrm{pH}>6)$ can form more negatively-charged $\mathrm{Fe}(\mathbb{I})(\mathrm{OH}) \mathrm{L}^{2-}$, which is 
expected to have a larger solvation shell compared to $\mathrm{Fe}(\mathrm{I}) \mathrm{L}^{-}$, the kinetic current started to decrease. This may be ascribed to the increase in local concentration of highly-hydroxylated $\mathrm{Fe}(\mathrm{II})(\mathrm{OH})_{2} \mathrm{~L}^{2-}$ during anodic polarization, which has a potential risk of precipitation.

RDE measurements were obtained using Pt and glassy carbon electrodes in the solution containing $\mathrm{Fe}_{\mathrm{aq}}{ }^{2+3+}$ under acidic conditions and compared to Fe-HEDTA (Figure S2). The onset potential of Fe-HEDTA appeared more negative than of $\mathrm{Fe}_{\mathrm{aq}}$ as discussed in the previous section (Figure 1a), which is the advantage of the present system to demonstrate the coproduction of hydrogen. A higher diffusion-limiting current density was observed with $\mathrm{Fe}_{\mathrm{aq}}$ compared to Fe-HEDTA, which came from their molarities ( $0.34 \mathrm{~mol} \mathrm{~L}^{-1}$ and $0.44 \mathrm{~mol} \mathrm{~L}^{-1}$, respectively) and their diffusion coefficients. The diffusion coefficient is described by the Stokes-Einstein equation (Eq. 18). 


$$
D=\frac{k T}{3 \pi d \mu}
$$

where $k$ is the Boltzmann constant, $d$ is the effective hydrodynamic diameter of the hydrated ion (Stokes diameter), which takes into account all the $\mathrm{H}_{2} \mathrm{O}$ molecules carried in the hydration sphere, and $\mu$ is the dynamic viscosity of the electrolyte. Although the Stokes diameter of $\mathrm{Fe}^{2+}$-HEDTA has not been reported, those for $\mathrm{Fe}^{2+}{ }_{\text {aq }}$ and $\mathrm{Fe}^{2+}$-EDTA are reported to be 6.8 and $8.4 \AA$, respectively. ${ }^{46,47}$ The charge of the ion is also known to play a role to the hydration. Since the predominant ferrous complexes are FeHEDTA $^{-}$and Fe-EDTA ${ }^{2-}$ at $\mathrm{pH}$ 5, the Stokes diameter of Fe-HEDTA ${ }^{-}$may be smaller than that of Fe-EDTA ${ }^{2-}$. The measured dynamic viscosities were 6.0 and $1.6 \mathrm{mPa}$ s for the solutions containing Fe-HEDTA and Fe $\mathrm{aq}_{\mathrm{aq}}$, respectively. As a result, the diffusion coefficient of $\mathrm{Fe}^{2+} \mathrm{HEDTA}$ is expected to be lower than that of $\mathrm{Fe}^{2+}$ aq mainly due to the dynamic viscosity. The kinetic current was evaluated using Koutecký-Levich analysis and the resulting Tafel plot is shown in Figure S2b. The kinetic current densities were similar between $\mathrm{Fe}_{\mathrm{aq}}$ and Fe-HEDTA. The kinetic current of Pt appeared approximately four to six times higher than that of the glassy carbon for both redox couples. The ratios 
of the rate constant on glassy carbon against platinum are reported to be $0.15-0.28$,

0.13 , and 0.20 for $\mathrm{Fe}^{2+/ 3+}, \mathrm{Ce}^{3+/ 4+}$, and $\mathrm{Fe}(\mathrm{CN})_{6}^{4-/ 3-}$ redox couples, respectively, ${ }^{48}$ which agrees with the observed difference for Fe-HEDTA between the glassy carbon and platinum in this study. The intrinsic difference between Pt and glassy carbon may arise from the density of state (DOS) of the electrode materials, which is explained in a quantum mechanical manner, ${ }^{49}$ rather than adsorption energy of intermediate, which is often employed for electrocatalytic reactions, such as hydrogen evolution. That detail is out of the scope of the present study because the diffusion overpotential has a major contribution even with the glassy carbon.

\section{Electrochemical measurements in various buffers. Because Fe-HEDTA provides a}

$\mathrm{pH}$-independent thermodynamic voltage to perform redox oxidation and HER in the $\mathrm{pH}$ range from 2 to 8 and the kinetic current becomes highest in the medium $\mathrm{pH}$ range (46), as shown in Figure 1a and 4c, respectively, this study focuses on neutral $\mathrm{pH} 5$ where the supporting buffer is required to minimize the local pH shift during the proton-coupled electron transfer. The impact of the supporting buffer species towards the diffusionlimiting current and the kinetic current is here studied. Under unbuffered conditions, 
hysteresis was observed during cyclic voltammetry, which could not be minimized by decreasing the scan rate (Figure S3), while buffered conditions provide steady-state current regardless of the scan direction and buffer species except for $0.5 \mathrm{~mol} \mathrm{~kg}^{-1}$ malonate (Figure 5a). Although phosphate is a popular buffer for water splitting under neutral $\mathrm{pH}$ conditions, it cannot be applied to the current system because it precipitates with metal cations. It is clear that the smaller organic buffer showed the higher diffusionlimiting current. Koutecký-Levich analysis was performed to isolate the contribution of the diffusion and kinetic currents. Since the activity coefficients of the concentrated redox are difficult to determine, $D \gamma^{3 / 2}$ was obtained from the slope of the KouteckýLevich plot and used as an indicator of the diffusion contribution. The obtained $D_{\gamma}^{3 / 2}$ are shown in Figure $5 \mathrm{~b}$ with the corresponding dynamic viscosities. The obtained $D \gamma^{3 / 2}$ shows a linear dependence respective to the reciprocal of the dynamic viscosity, in agreement with the Stokes-Einstein equation (Eq. 18). There was no clear dependence of the kinetics on the viscosity in Figure $5 c$ despite a kinetic viscosity effect, where the viscosity of solution alters the relaxation time of their outer solvation shell, was reported with $\mathrm{Fe}(\mathrm{CN})_{6}^{50}$ and $\mathrm{Cr}_{-} \mathrm{EDTA}^{51}$, as shown in Eq. 19. 


$$
k^{0}=A \mu^{-B} \exp \left(-\Delta G_{0}^{*} / R T\right)
$$

where $k^{0}$ is the rate constant of electron transfer and $A$ and $B$ are constants $(0<B<1)$.

The absence of a kinetic viscosity effect may arise from a larger inner sphere activation barrier or weak adiabaticity52,53 for Fe-HEDTA redox, which agrees with the poor kinetics compared to $\mathrm{Fe}(\mathrm{CN})_{6}$ observed in Figure $2 \mathrm{~b}$. 
(a)

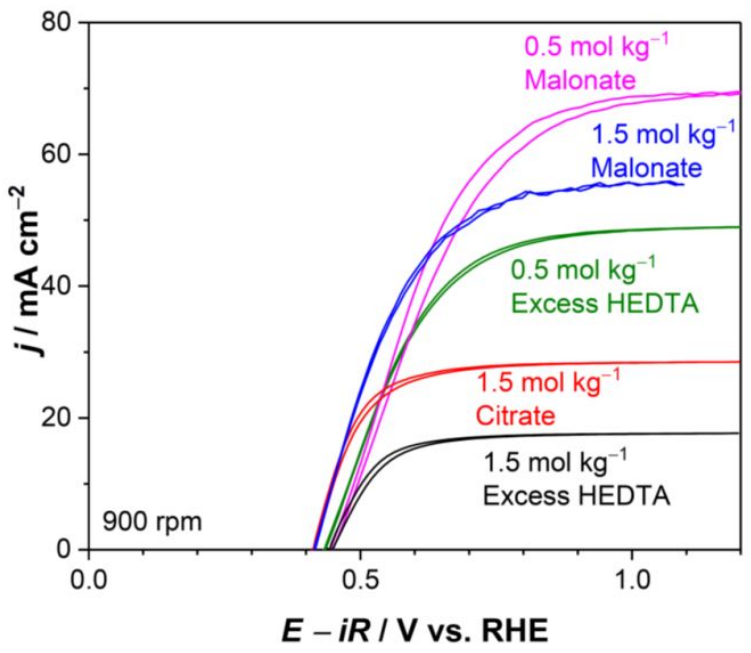

(c)

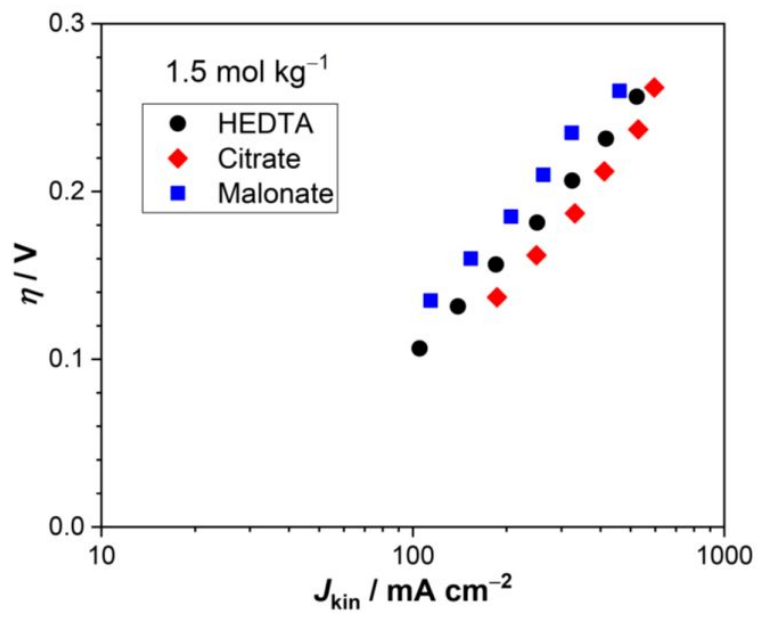

(b)

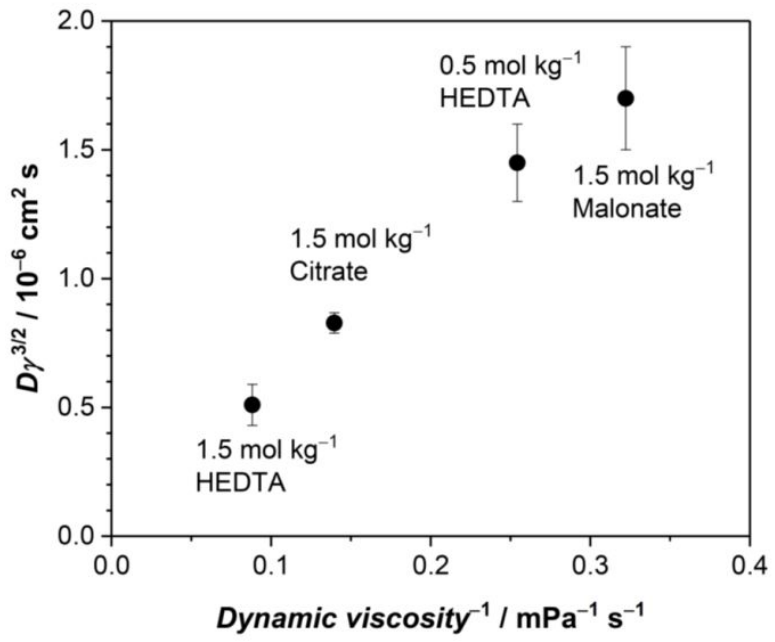

Figure 5. (a) Cyclic voltammograms measured using a glassy carbon rotating disk electrode in a solution containing a total of $1.0 \mathrm{~mol} \mathrm{~kg}^{-1} \mathrm{Fe}-\mathrm{HEDTA}$ with different buffers (HEDTA, citrate, and malonate). Redox solutions have $50 \%$ reduced species and $50 \%$ oxidized species ( $\left.\mathrm{pH}=5,900 \mathrm{rpm}, 50 \mathrm{mV} \mathrm{s}^{-1}, 298 \mathrm{~K}\right)$. (b) The relationship between 
$D \gamma^{3 / 2}$ and the dynamic viscosity. (c) Tafel plot of kinetic current obtained after the

Koutecký-Levich analysis.

Temperature effects on Fe-HEDTA redox electrochemistry. Controlling the temperature

of the electrolyte is an alternative approach to improving the diffusion and the kinetics.

Since commercialized homogeneous processes to oxidize $\mathrm{H}_{2} \mathrm{~S}$ in liquid phase operate

at $40-60^{\circ} \mathrm{C},{ }^{12,54}$ it is reasonable to perform the electrochemical regeneration of redox

at elevated temperatures. Here, temperature dependence was investigated with $1.5 \mathrm{~mol}$

$\mathrm{kg}^{-1}$ malonate buffer because hysteresis got obvious at elevated temperature in the

presence of $0.5 \mathrm{~mol} \mathrm{~kg}^{-1}$ malonate buffer (Figure S4). Cyclic voltammograms of a

glassy carbon disk electrode in the redox solution at different temperatures are shown in

Figure 6a. 
(a)

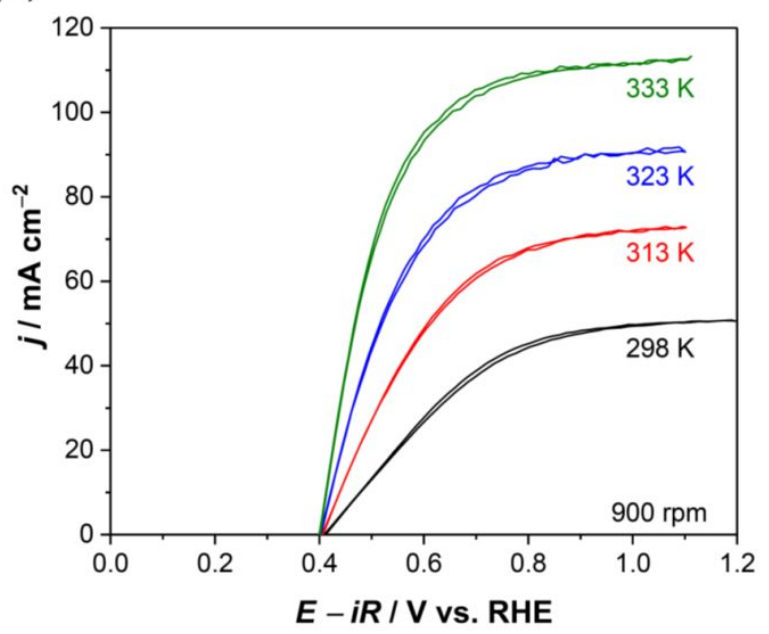

(c)

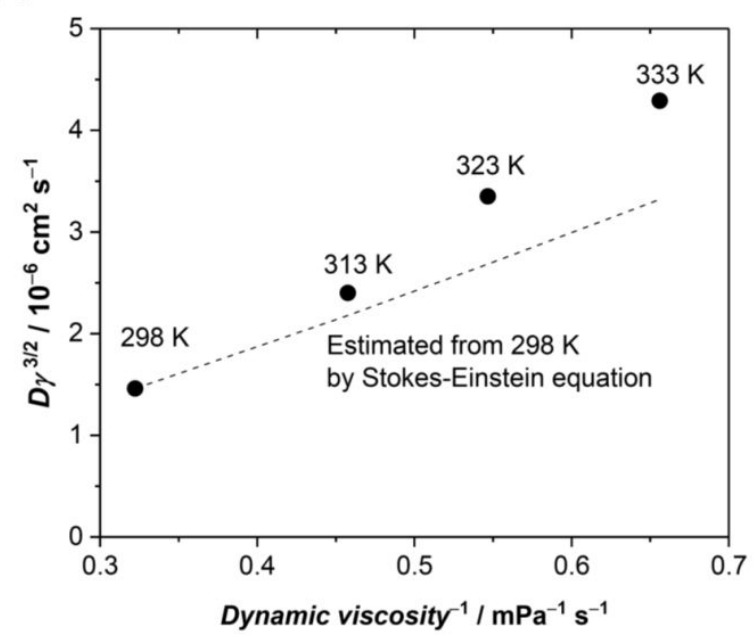

(b)

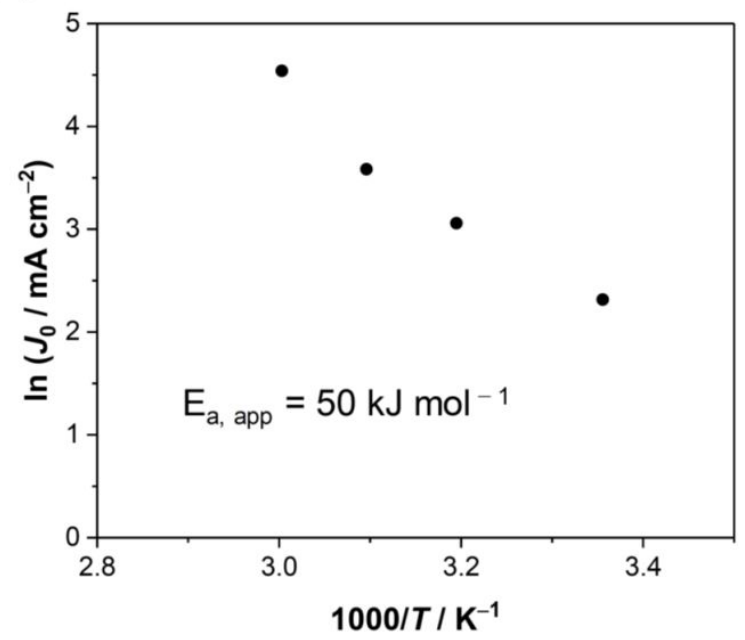

Figure 6. (a) Cyclic voltammograms from the glassy carbon disk electrode in $0.5 \mathrm{~mol}$ $\mathrm{kg}^{-1}$ of $\mathrm{Fe}^{2+}$-HEDTA and $0.5 \mathrm{~mol} \mathrm{~kg}^{-1}$ of $\mathrm{Fe}^{3+}$-HEDTA solution measured at $50 \mathrm{mV} \mathrm{s}^{-1}$ under $\mathrm{Ar}$ atmosphere at different temperatures. $1.5 \mathrm{~mol} \mathrm{~kg}^{-1}$ of malonic acid was added as a buffer and the $\mathrm{pH}$ was adjusted to 5. (b) Arrhenius plot of exchange current density obtained from Tafel plots. (c) Temperature dependence of $D \gamma^{3 / 2}$ and dynamic viscosity. 
$D \gamma^{3 / 2}$ estimated from $298 \mathrm{~K}$ and the dynamic viscosity using the Stokes-Einstein equation is shown as the open symbol.

The diffusion-limiting current clearly improved and the current increased sharply by increasing the temperature, which implies improved diffusion and kinetics at elevated temperatures. The contributions from diffusion and kinetics were further isolated by the Koutecký-Levich analysis. The apparent activation energy was obtained from an Arrhenius plot of the exchange current density (Figure 6b). The activation energy obtained for Fe-HEDTA was $50 \mathrm{~kJ} \mathrm{~mol}^{-1}$ while that for $\mathrm{Fe}(\mathrm{CN})_{6}$ was reported to be $31 \mathrm{~kJ}$ $\mathrm{mol}^{-1}, 55$ which agrees with the poor kinetics of Fe-HEDTA compared to $\mathrm{Fe}(\mathrm{CN})_{6}$ observed in Figure 2b. $D \gamma^{3 / 2}$ was obtained from the slope of the Koutecký-Levich plot and shown with corresponding dynamic viscosity (Figure 6c). Since the viscosity decreases at elevated temperatures as shown, the diffusion coefficient is expected to increase. In order to elucidate the diffusion-contributing term $D \gamma^{3 / 2}$, estimation of $D \gamma^{3 / 2}$ was performed from the measured $D_{\gamma}^{3 / 2}$ at $298 \mathrm{~K}$ and measured dynamic viscosity at 
different temperatures following the Stokes-Einstein equation (Eq. 18) with the assumption that the activity coefficient and the Stokes diameter are constant. The $D \gamma^{3 / 2}$ estimated from the Stokes-Einstein equation, which is shown as a dashed line in Figure $6 \mathrm{c}$, appears lower than the measured ones. This deviation between the measured values and the estimated ones suggests that elevating temperature increased not only the diffusion coefficient but also the activity coefficient, which also helps to improve the diffusion-limiting current. Controlling the operational temperature is an attractive approach that can increase the diffusion-limiting current over two-fold.

As a summary, the obtained results are compared with the various reported redox candidates in Table 1. It can be found that the advantages of Fe-HEDTA among the proposed redox candidates are its relatively low redox potential $(<0.5 \mathrm{~V} v \mathrm{v}$. RHE) and high solubility $\left(1 \mathrm{~mol} \mathrm{~kg}^{-1}\right)$ in near neutral $\mathrm{pH}$ condition. The impact of supporting buffer and reaction temperature towards diffusion of dense redox is also summarized in Table 2, which clearly shows that low viscosity and elevated temperature help to improve diffusion term, $D \gamma^{3 / 2}$. 
Table 1. Comparison with reported redox candidates.

\begin{tabular}{|c|c|c|c|c|}
\hline Redox couple & $\begin{array}{l}\text { E/V } \\
\text { vs. RHE }\end{array}$ & $\begin{array}{l}\text { Supporting } \\
\text { electrolyte } \\
\text { or } \mathrm{pH}\end{array}$ & $\begin{array}{l}\text { Concentration } \\
\text { of redox }\end{array}$ & Reference \\
\hline $\mathrm{Fe}^{2+/ 3+}$-HEDTA & 0.43 & $\begin{array}{l}1.5 \mathrm{~mol} \mathrm{~kg}^{-1} \\
\text { malonate buffer }(\mathrm{pH} \\
=5)\end{array}$ & $1 \mathrm{~mol} \mathrm{~kg}^{-1}$ & This work \\
\hline $\mathrm{Fe}_{\mathrm{aq}}{ }^{2+/ 3+}$ & 0.6 & $0.5 \mathrm{~mol} \mathrm{~L}^{-1} \mathrm{H}_{2} \mathrm{SO}_{4}$ & $1 \mathrm{~mol} \mathrm{~L}^{-1}$ & 19 \\
\hline $\mathrm{Fe}^{2+/ 3+}-\mathrm{EDTA}$ & 0.2 & $\mathrm{pH}=8.5$ & $0.1 \mathrm{~mol} \mathrm{~L}^{-1}$ & 22 \\
\hline $\begin{array}{l}\mathrm{H}_{5}\left(\mathrm{PMo}_{2} \mathrm{MoVI}_{10} \mathrm{O}_{40}\right) \\
/ \mathrm{H}_{3}\left(\mathrm{PMo}{ }_{12} \mathrm{O}_{40}\right)\end{array}$ & 0.8 & $0.5 \mathrm{~mol} \mathrm{~L}^{-1} \mathrm{H}_{2} \mathrm{SO}_{4}$ & $0.25 \mathrm{~mol} \mathrm{~L}^{-1}$ & 19 \\
\hline $\mathrm{I} / \mathrm{I}_{3}^{-}$(Acid) & $0.53(\mathrm{pH}=$ & $5.5 \mathrm{~mol} \mathrm{~L}^{-1} \mathrm{HI}$ & $5.5 \mathrm{~mol} \mathrm{~L}^{-1}$ & $14,56,57$ \\
\hline $\mathrm{I} / \mathrm{IO}_{3}^{-}$(Base) & $\begin{array}{l}0) \\
1.08 \\
(\mathrm{pH}=14)\end{array}$ & $1.6 \mathrm{~mol} \mathrm{~L}^{-1} \mathrm{OH}^{-}$ & $1.525 \mathrm{~mol} \mathrm{~L}^{-1}$ & \\
\hline$(\mathrm{VO})^{2+} /\left(\mathrm{VO}_{2}\right)^{+}$ & 0.99 & $7 \mathrm{~mol} \mathrm{~kg}^{-1} \mathrm{H}^{+}$ & $1 \mathrm{~mol} \mathrm{~kg}^{-1}$ & 18 \\
\hline
\end{tabular}

Table 2. Summary of the present work to improve the diffusion. 


\begin{tabular}{|c|c|c|c|c|}
\hline Redox couple & $\begin{array}{l}\text { Supporting } \\
\text { buffer }\end{array}$ & $\begin{array}{l}\text { Temperature } \\
\text { / K }\end{array}$ & $\begin{array}{l}\text { Dynamic } \\
\text { viscosity / } \mathrm{mPa} \\
\mathrm{s}\end{array}$ & $\begin{array}{l}D \gamma \\
/ 10^{-6} \mathrm{~cm}^{2} \mathrm{~s}\end{array}$ \\
\hline $1 \mathrm{~mol} \mathrm{~kg}^{-1}$ & $1.5 \mathrm{~mol} \mathrm{~kg}^{-1}$ & & 11 & 0.5 \\
\hline & $\begin{array}{l}1.5 \mathrm{~mol} \mathrm{~kg}^{-1} \\
\text { citrate }\end{array}$ & 298 & 7.1 & 0.8 \\
\hline & & & 3.1 & 1.7 \\
\hline & malonate & 313 & 2.2 & 2.4 \\
\hline & & 333 & 1.5 & 4.3 \\
\hline
\end{tabular}

\section{CONCLUSIONS}

In this study, we demonstrate tuning the redox potential of Fe-containing metal

complexes based on their equilibrium constants. Quantitative analysis of the oxidation

of redox species revealed that diffusion overpotential greatly contributes to the overall

electrochemical performance while ubiquitous carbon electrodes have sufficient 
kinetics. The Fe-HEDTA redox couple was determined to be a suitable candidate due to its $\mathrm{pH}$-independent thermodynamic voltage to perform redox oxidation and HER (approximately $0.43 \mathrm{~V}$ ) and the remarkable solubility of both its oxidized and reduced species $\left(1 \mathrm{~mol} \mathrm{~kg}^{-1}\right)$ in the neutral $\mathrm{pH}$ range, which helps to increase the diffusionlimiting current. In addition to the redox couples itself, the supporting buffer also plays an important role in determining the diffusion-limiting current density, thereby revealing that malonate buffer is suitable for the application under a neutral $\mathrm{pH}$ condition $(\mathrm{pH}=5)$ due to its low viscosity. Elevated temperature further helps to improve not only the diffusion coefficient of the redox but also the activity coefficient. These insights will certainly help to design an electrochemical system with a HER and the oxidation of soluble redox species to achieve redox-mediated $\mathrm{H}_{2} \mathrm{~S}$ splitting.

\section{ASSOCIATED CONTENT}

Supporting Information. The following files are available free of charge.

Table of equilibrium constants (Table S1), Supplementary electrochemical 
measurements (Figures S1-S4) (PDF)

\section{AUTHOR INFORMATION}

Corresponding Author

* Kazuhiro Takanabe, email: takanabe@chemsys.t.u-tokyo.ac.jp

\section{ACKNOWLEDGMENT}

The research reported in this paper was supported by the King Abdullah University of

Science and Technology.

\section{REFERENCES}

(1) Jia, J.; Seitz, L. C.; Benck, J. D.; Huo, Y.; Chen, Y.; Ng, J. W. D.; Bilir, T.; Harris, J.

S.; Jaramillo, T. F. Solar Water Splitting by Photovoltaic-Electrolysis with a Solar-

to-Hydrogen Efficiency over 30\%. Nat. Commun. 2016, 7, 13237, DOI

10.1038/ncomms13237.

(2) Luo, J.; Im, J. H.; Mayer, M. T.; Schreier, M.; Nazeeruddin, M. K.; Park, N. G.; Tilley, 
S. D.; Fan, H. J.; Grätzel, M. Water Photolysis at $12.3 \%$ Efficiency via Perovskite Photovoltaics and Earth-Abundant Catalysts. Science (80-. ). 2014, 345 (6204), 1593-1596, DOI 10.1126/science.1258307.

(3) Kageshima, Y.; Shinagawa, T.; Kuwata, T.; Nakata, J.; Minegishi, T.; Takanabe, K.; Domen, K. A Miniature Solar Device for Overall Water Splitting Consisting of Series-Connected Spherical Silicon Solar Cells. Sci. Rep. 2016, 6, 1-12, DOI 10.1038/srep24633.

(4) Zhang, B.; Zheng, X.; Voznyy, O.; Comin, R.; Bajdich, M.; Arquer, F. P. G. De; Dinh, C. T.; Fan, F.; Yuan, M.; Janmohamed, A.; et al. Homogeneously Dispersed Multimetal Oxygen-Evolving Catalysts. Science 2016, 352 (6283), 333-338, DOI 10.1126/science.aaf1525.

(5) Zhang, P.; Li, L.; Nordlund, D.; Chen, H.; Fan, L.; Zhang, B.; Sheng, X.; Daniel, Q.; Sun, L. Dendritic Core-Shell Nickel-Iron-Copper Metal/Metal Oxide Electrode for Efficient Electrocatalytic Water Oxidation. Nat. Commun. 2018, 9 (1), 1-10, DOI 10.1038/s41467-017-02429-9. 
(6) You, B.; Liu, X.; Jiang, N.; Sun, Y. A General Strategy for Decoupled Hydrogen

Production from Water Splitting by Integrating Oxidative Biomass Valorization. $J$.

Am. Chem. Soc. 2016, 138(41), 13639-13646, DOI 10.1021/jacs.6b07127.

(7) Liu, W.-J.; Dang, L.; Xu, Z.; Yu, H.-Q.; Jin, S.; Huber, G. W. Electrochemical

Oxidation of 5-Hydroxymethylfurfural with NiFe Layered Double Hydroxide (LDH)

Nanosheet Catalysts. ACS Catal. 2018, 5533-5541, DOI

10.1021/acscatal.8b01017.

(8) Li, W.; Jiang, N.; Hu, B.; Liu, X.; Song, F.; Han, G.; Jordan, T. J.; Hanson, T. B.;

Liu, T. L.; Sun, Y. Electrolyzer Design for Flexible Decoupled Water Splitting and

Organic Upgrading with Electron Reservoirs. Chem 2018, 4 (3), 637-649, DOI

10.1016/j.chempr.2017.12.019.

(9) Fuku, K.; Miyase, Y.; Miseki, Y.; Gunji, T.; Sayama, K. WO ${ }_{3} /$ BiVO $_{4}$ Photoanode

Coated with Mesoporous $\mathrm{Al}_{2} \mathrm{O}_{3}$ Layer for Oxidative Production of Hydrogen

Peroxide from Water with High Selectivity. RSC Adv. 2017, 7 (75), 47619-47623,

DOI 10.1039/C7RA09693C. 
(10) Fuku, K.; Miyase, Y.; Miseki, Y.; Funaki, T.; Gunji, T.; Sayama, K. Photoelectrochemical Hydrogen Peroxide Production from Water on a $\mathrm{WO}_{3} / \mathrm{BiVO}$ ${ }_{4}$ Photoanode and from $\mathrm{O}_{2}$ on an Au Cathode Without External Bias. Chem. - An Asian J. 2017, 12(10), 1111-1119, DOI 10.1002/asia.201700292.

(11) Nakajima, T.; Hagino, A.; Nakamura, T.; Tsuchiya, T.; Sayama, K. WO 3 Nanosponge Photoanodes with High Applied Bias Photon-to-Current Efficiency for Solar Hydrogen and Peroxydisulfate Production. J. Mater. Chem. A 2016, 4 (45), 17809-17818, DOI 10.1039/C6TA07997K.

(12) Wubs, H. J.; Beenackers, A. A. C. M. Kinetics of $\mathrm{H}_{2} \mathrm{~S}$ Absorption into Aqueous Ferric Solutions of EDTA and HEDTA. A/ChE J. 1994, 40 (3), 433-444, DOI 10.1002/aic.690400307.

(13) Kohl, A. L.; Nielsen, R. B. Liquid Phase Oxidation Processes for Hydrogen Sulfide Removal. Gas Purif. 1997, 731-865, DOI 10.1016/B978-088415220-0/50009-4.

(14) Pourbaix, M. Atlas of Electrochemical Equilibria in Aqueous Solution, 2nd ed.; 
National Association of Corrosion, 1974.

(15) Ateya, B. G.; Alkharafi, F. M.; Alazab, A. S.; Abdullah, A. M. Kinetics of the Electrochemical Deposition of Sulfur from Sulfide Polluted Brines. J. Appl. Electrochem. 2007, 37(3), 395-404, DOI 10.1007/s10800-006-9270-4.

(16) Anani, a. a.; Mao, Z.; White, R. E.; Srinivasan, S.; Appleby, A. J. Electrochemical Production of Hydrogen and Sulfur by Low-Temperature Decomposition of Hydrogen Sulfide in an Aqueous Alkaline Solution. J. Electrochem. Soc. 1990, 137 (9), 2703, DOI 10.1149/1.2087021.

(17) Mizuta, S.; Kondo, W.; Fujii, K.; lida, H.; Isshiki, S.; Noguchi, H.; Kikuchi, T.; Sue, H.; Sakai, K. Hydrogen Production from Hydrogen Sulfide by the Iron-Chlorine Hybrid Process. Ind. Eng. Chem. Res. 1991, 30 (7), 1601-1608, DOI 10.1021/ie00055a028.

(18) Huang, H.; Yu, Y.; Chung, K. H. Recovery of Hydrogen and Sulfur by Indirect Electrolysis of Hydrogen Sulfide. Energy and Fuels 2009, 23 (9), 4420-4425, DOI 


\subsection{1/ef900424a.}

(19) Ma, W.; Han, J.; Yu, W.; Yang, D.; Wang, H.; Zong, X.; Li, C. Integrating Perovskite Photovoltaics and Noble-Metal-Free Catalysts toward Efficient Solar Energy Conversion and $\mathrm{H}_{2} \mathrm{~S}$ Splitting. ACS Catal. 2016, 6 (9), 6198-6206, DOI 10.1021/acscatal.6b01772.

(20) Kim, K.; Song, D.; Han, J. I. A Liquid Redox Sulfur Recovery Process Based on Heteropoly Molybdophosphate (HPMo) with Electricity Generation. Chem. Eng. J. 2014, 241, 60-65, DOI 10.1016/j.cej.2013.12.007.

(21) Zong, X.; Han, J.; Seger, B.; Chen, H.; Lu, G.; Li, C.; Wang, L. An Integrated Photoelectrochemical-Chemical Loop for Solar-Driven Overall Splitting of Hydrogen Sulfide. Angew. Chemie - Int. Ed. 2014, 53 (17), 4399-4403, DOI 10.1002/anie.201400571.

(22) Ma, W.; Wang, H.; Yu, W.; Wang, X.; Xu, Z.; Zong, X.; Li, C. Achieving Simultaneous $\mathrm{CO}_{2}$ and $\mathrm{H}_{2} \mathrm{~S}$ Conversion via a Coupled Solar-Driven 
Electrochemical Approach on Non-Precious Catalysts. Angew. Chemie Int. Ed.

2018, 57(13), 3473-3477, DOI 10.1002/anie.201713029.

(23) Garcia-Esparza, A. T.; Shinagawa, T.; Ould-Chikh, S.; Qureshi, M.; Peng, X.; Wei,

N.; Anjum, D. H.; Clo, A.; Weng, T. C.; Nordlund, D.; et al. An Oxygen-Insensitive

Hydrogen Evolution Catalyst Coated by a Molybdenum-Based Layer for Overall

Water Splitting. Angew. Chemie - Int. Ed. 2017, 56 (21), 5780-5784, DOI

10.1002/anie.201701861.

(24) Qureshi, M.; Shinagawa, T.; Tsiapis, N.; Takanabe, K. Exclusive Hydrogen

Generation by Electrocatalysts Coated with an Amorphous Chromium-Based Layer

Achieving Efficient Overall Water Splitting. ACS Sustain. Chem. Eng. 2017, 5 (9),

8079-8088, DOI 10.1021/acssuschemeng.7b01704.

(25) Bau, J. A.; Takanabe, K. Ultrathin Microporous $\mathrm{SiO}_{2}$ Membranes Photodeposited on Hydrogen Evolving Catalysts Enabling Overall Water Splitting. ACS Catal. 2017, 7(11), 7931-7940, DOI 10.1021/acscatal.7b03017. 
(26) Kim, K. J.; Kim, Y. J.; Kim, J. H.; Park, M. S. The Effects of Surface Modification on Carbon Felt Electrodes for Use in Vanadium Redox Flow Batteries. Mater. Chem. Phys. 2011, 131 (1-2), 547-553, DOI 10.1016/j.matchemphys.2011.10.022.

(27) Carney, T. J.; Collins, S. J.; Moore, J. S.; Brushett, F. R. Concentration-Dependent Dimerization of Anthraquinone Disulfonic Acid and Its Impact on Charge Storage. Chem. Mater. 2017, 29(11), 4801-4810, DOI 10.1021/acs.chemmater.7b00616.

(28) Huskinson, B.; Marshak, M. P.; Suh, C.; Er, S.; Gerhardt, M. R.; Galvin, C. J.; Chen, X.; Aspuru-Guzik, A.; Gordon, R. G.; Aziz, M. J. A Metal-Free Organic-Inorganic Aqueous Flow Battery. Nature 2014, 505 (7482), 195-198, DOI 10.1038/nature12909.

(29) Wedege, K.; Dražević, E.; Konya, D.; Bentien, A. Organic Redox Species in Aqueous Flow Batteries: Redox Potentials, Chemical Stability and Solubility. Sci. Rep. 2016, 6, 1-13, DOI 10.1038/srep39101.

(30) Shimizu, K.; Hutcheson, R.; Engelmann, M. D.; Francis Cheng, I. Cyclic 
Voltammetric and Aqueous Equilibria Model Study of the $\mathrm{pH}$ Dependant Iron(II/III)Ethylenediamminetetraacetate Complex Reduction Potential. J. Electroanal. Chem. 2007, 603(1), 44-50, DOI 10.1016/j.jelechem.2007.01.027.

(31) Harrington, J. M.; Crumbliss, A. L. The Redox Hypothesis in Siderophore-Mediated Iron Uptake. BioMetals 2009, 22 (4), 679-689, DOI 10.1007/s10534-009-9233-4.

(32) Rizvi, M. A.; Syed, R. M.; Khan, B. Complexation Effect on Redox Potential of Iron(III) - Iron(II) Couple: A Simple Potentiometric Experiment. J. Chem. Educ. 2011, $88(2)$, 220-222, DOI 10.1021/ed100339g.

(33) Martell, A. E.; Smith, R. M. Critical Stability Constants; Plenum Press: New York, 1982.

(34) Skochdopole, R.; Chaberek, S. Iron Chelates of NHydroxyethylethylenediaminetriacetic Acid. J. Inorg. Nucl. Chem. 1959, 11 (3), 222-233, DOI 10.1016/0022-1902(59)80248-7.

(35) Gustafson, R. L.; Martell, A. E. Hydrolytic Tendencies of Ferric Chelates. J. Phys. 
Chem. 1963, 67(3), 576-582, DOI 10.1021/j100797a008.

(36) Martell, A. E.; Motekaitis, R. J.; Chen, D.; Hancock, R. D.; McManus, D. Selection of $\mathrm{New} \mathrm{Fe}(\mathrm{III} / \mathrm{Fe}(\mathrm{II})$ Chelating Agents as Catalysts for the Oxidation of Hydrogen Sulfide to Sulfur by Air. Can. J. Chem. 1996, 74(10), 1872-1879, DOI 10.1139/v96210.

(37) Hanania, G. I. H.; Irvine, D. H.; Eaton, W. A.; George, P. Thermodynamic Aspects of the Potassium Hexacyano-Ferrate(III)-(II) System. II. Reduction Potential. J. Phys. Chem. 1967, 71 (7), 2022-2030, DOI 10.1021/j100866a008.

(38) Krulic, D.; Fatouros, N.; Khoshtariya, D. E. Kinetic Data for the Hexacyanoferrate Couple on Platinum Electrode in Various Chlorides of Monovalent Cations. J. Chim. Phys 1998, 95, 497-512, DOI 10.1051/jcp.

(39) Kolthoff, I. M.; Tomsicek, W. J. The Oxidation Potential of the System Potassium Ferricyanide At Various lonic Strengths. J. Phys. 1935, 39 (7), 945-954, DOI 10.1021/j150367a004. 
(40) Eaton, W. A.; George, P.; Hanania, G. I. Thermodynamic Aspects of the Potassium Hexacyanoferrate(III)-(II) System. I. Ion Association. J. Phys. Chem. 1967, 71 (7), 2016-2021, DOI 10.1021/j100866a007.

(41) Meier, R.; Werner, G. Investigation of the Vanadium(III)/Vanadium(II)/ N(Hydroxyethyl)Ethylenediaminetriacetic Acid System by Cyclic Voltammetry and Differential Pulse Polarography. Anal. Chim. Acta 1989, 219, 281-293, DOI 10.1016/S0003-2670(00)80359-1.

(42) Marcus, R. A. On the Theory of Oxidation-Reduction Reactions Involving Electron Transfer. I. J. Chem. Phys. 1956, 24 (5), 966-978, DOI 10.1063/1.1742723.

(43) Bard, A. J.; Faulkner, L. R. Electrochemical Methods Fundamentals and Applications, 2nd editio.; John Wiley \& Sonc, Inc.: New York, 2010.

(44) Gong, K.; Xu, F.; Grunewald, J. B.; Ma, X.; Zhao, Y.; Gu, S.; Yan, Y. All-Soluble AllIron Aqueous Redox-Flow Battery. ACS Energy Lett. 2016, 1 (1), 89-93, DOI 10.1021/acsenergylett.6b00049. 
(45) Yang, Z.; Tong, L.; Tabor, D. P.; Beh, E. S.; Goulet, M. A.; De Porcellinis, D.;

Aspuru-Guzik, A.; Gordon, R. G.; Aziz, M. J. Alkaline Benzoquinone Aqueous Flow

Battery for Large-Scale Storage of Electrical Energy. Adv. Energy Mater. 2018, 8

(8), 1-9, DOI 10.1002/aenm.201702056.

(46) Nightingale, E. R. Phenomenological Theory of Ion Solvation. Effective Radii of Hydrated lons. J. Phys. Chem. 1959, 63 (9), 1381-1387, DOI 10.1021/j150579a011.

(47) Leaist, D. G.; Hao, L. Tracer Diffusion of Some Metal lons and Metal-EDTA Complexes in Aqueous Sodium Chloride Solutions. J. Chem. Soc. Faraday Trans. 1994, 90 (1), 133-136, DOI 10.1007/BF02670151.

(48) Taylor, R. J.; Humffray, a. a. Electrochemical Studies on Glassy Carbon Electrodes. J. Electroanal. Chem. Interfacial Electrochem. 1973, 42 (3), 347-354, DOI 10.1016/S0022-0728(73)80324-9.

(49) Gosavi, S.; Marcus, R. A. Nonadiabatic Electron Transfer at Metal Surfaces. J. 
Phys. Chem. B2000, 104, 2067, DOI 10.1021/jp9933673.

(50) Khoshtariya, D. E.; Dolidze, T. D.; Krulic, D.; Fatouros, N.; Devilliers, D. Solvent Friction Mechanism of an Elementary Charge-Transfer Step and Cation-Regulated Preequilibrium for a Pt/Fe $(\mathrm{CN})_{6}{ }^{4-/ 3-}$ Electrode Process. J. Phys. Chem. B 1998, 102 (40), 7800-7806, DOI 10.1021/jp981064n.

(51) Zhang, X.; Yang, H.; Bard, A. J. Variation of The Heterogeneous Electron Transfer Rate Constant with Solution Viscosity: Reduction of Aqueous Solutions of CrIII(Edta)- At A Mercury Electrode. J. Am. Chem. Soc. 1987, 109 (7), 1916-1920, DOI 10.1021/ja00241a005.

(52) Fawcett, W. R.; Opallo, M. The Kinetics of Heterogeneous Electron Transfer Reaction in Polar Solvents. Angew. Chemie Int. Ed. English 1994, 33 (21), 21312143, DOI 10.1002/anie.199421311.

(53) Fawcett, W. R.; Opallo, M. On the Differences in the Magnitude of the Observed Solvent Effect in the Kinetics of Simple Heterogeneous Electron Transfer 
Reactions. J. Electroanal. Chem. 1993, 349 (1-2), 273-284, DOI 10.1016/00220728(93)80178-K.

(54) Demmink, J. F.; Beenackers, A. A. C. M. Gas Desulfurization with Ferric Chelates of EDTA and HEDTA: New Model for the Oxidative Absorption of Hydrogen Sulfide. Ind. Eng. Chem. Res. 1998, 37(4), 1444-1453, DOI 10.1021/ie970427n.

(55) Peter, L. M.; Dürr, W.; Bindra, P.; Gerischer, H. The Influence of Alkali Metal Cations on the Rate of the $\mathrm{Fe}(\mathrm{CN}) 64-/ \mathrm{Fe}(\mathrm{CN}) 63-$ Electrode Process. J. Electroanal. Chem. Interfacial Electrochem. 1976, 71 (1), 31-50, DOI 10.1016/S0022-0728(76)80288-4.

(56) KALINA, D.; MAASJR, E. Indirect Hydrogen Sulfide Conversion-I. An Acidic Electrochemical Process. Int. J. Hydrogen Energy 1985, 10 (3), 157-162, DOI 10.1016/0360-3199(85)90022-9.

(57) KALINA, D.; MAASJR, E. Indirect Hydrogen Sulfide Conversion—II. A Basic Electrochemical Process. Int. J. Hydrogen Energy 1985, 10 (3), 163-167, DOI 
10.1016/0360-3199(85)90023-0.

Graphical abstract:

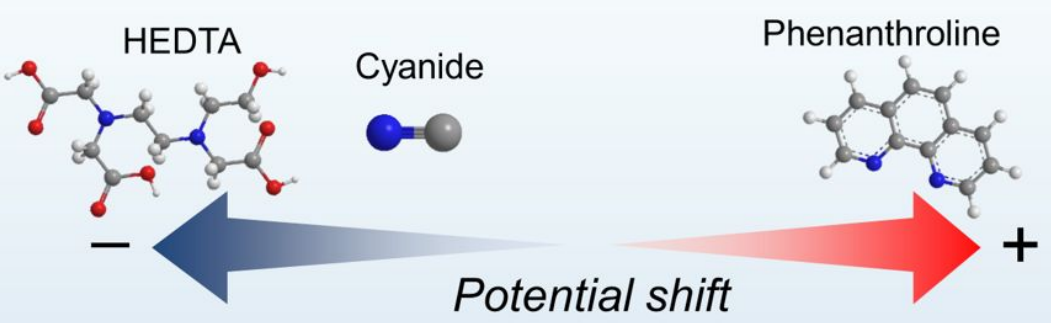

SYNOPSIS: Redox candidates for $\mathrm{H}_{2} \mathrm{~S}$ splitting are discussed with respect to the thermodynamics and the diffusion limitation. 